\title{
The Quantitative Role of Child Care for Female Labor Force Participation and Fertility
}

\author{
Alexander Bick* \\ Goethe University Frankfurt
}

October 4, 2011

\begin{abstract}
Consistent with facts for a cross-section of OECD countries, I document that the labor force participation rate of West German mothers with children aged zero to two exceeds the corresponding child care enrollment rate whereas the opposite is true for mothers with children aged three to mandatory school age. I develop a life-cycle model that explicitly accounts for this agedependent relationship through various types of non-paid and paid child care. The calibrated version of the model is used to evaluate two policy reforms concerning the supply of subsidized child care for children aged zero to two. These counterfactual policy experiments suggest that the lack of subsidized child care constitutes indeed for some females a barrier to participate in the labor market and depresses fertility.
\end{abstract}

Keywords: Child Care, Fertility, Life-cycle Female Labor Supply

JEL classification: D10, J13, J22

*I am indebted to Dirk Krueger for his guidance and advise at all stages of this project. I thank Nicola FuchsSchündeln for detailed comments and suggestions, and Sekyu Choi, Angela Fiedler, Jorgo Georgiadis, Jeremy Greenwood, Fane Groes, Bertrand Gobillard, John Knowles, Alexander Ludwig, Michèle Tertilt, Monika Piazzesi, Sigrid Röhrs, Virginia Sánchez-Marcos, Martin Schneider, Petra Todd, Ken Wolpin, and participants at various seminars and conferences for helpful discussions. Financial support from the Cluster of Excellence "Normative Orders" at Goethe University Frankfurt and the German Academic Exchange Service (DAAD) is gratefully acknowledged. Part of this paper was written during a visit at the Economics Department of the University of Pennsylvania, Philadelphia. E-mail: bick@wiwi.uni-frankfurt.de 


\section{Introduction}

At the Barcelona meeting in March 2002, the European Council recommended that its member states remove "barriers and disincentives for female labor force participation by, inter alia, improving the provision of child care facilities", European Council (2002). Even quantitative targets for the level of provision were set. By 2010, the EU member states shall provide child care for $33 \%$ of all children younger than age three and for $90 \%$ of all children aged three to mandatory school age. In 2008, the German government passed a law that aims at implementing the target value for children younger than age three. The German Federal Ministry of Family Affairs, Senior Citizens, Women and Youth further motivated this target value by recognizing that for women "good conditions for the compatibility of family and working life are a prerequisite to fulfill their desired fertility level" and by "the exemplary standards in Western and Northern European countries, for which a relationship between child care enrollment, maternal employment and fertility is observed", see Sharma and Steiner (2008). Governments may provide child care and promote female labor force participation and fertility for several reasons, e.g. investment in children's human capital, gender equality or to alleviate the economic consequences of the demographic change for the labor market and social security system. In this paper I am after a more basic question, namely to quantify in how far (not) providing child care constitutes a barrier or disincentive for female labor force participation and fertility choices.

Figure 1 shows for a cross-section of EU countries (those which are also in the OECD) the significant positive correlation of the fraction of children aged zero to two enrolled in a paid child care arrangement, e.g. in form of a daycare center or a nanny, with the labor force participation rate of mothers with children aged zero to two and the total fertility rate. ${ }^{1}$ Clearly, these correlations do not necessarily reflect causality and (due to data availability) only display the actual enrollment rates and not the provision rates of child care. Hence, with regard to the main question asked in this paper these figures do not permit to draw conclusions on how far (not) providing child care constitutes a barrier or disincentive for female labor force participation and fertility choices. Moreover, the relationships crucially hinge on the age of the children. For children aged three to five the previously significant positive correlations become negative or much weaker and are no longer statistically significant, see Figure 2. This suggests a very different role of child care for maternal labor force participation decisions in the two age groups. In this context, Figures 1 and 2 reveal another important relationship. The labor force participation rate of mothers with children aged zero to two exceeds the corresponding child care enrollment rate on average by 29 percentage points. To the contrary, for mothers with children aged three to five the child care enrollment rate exceeds the maternal labor force participation rate on average by 19 percentage points. Put differently, paid child care is used heavily by non-working mothers (of children between age three and five) whereas a substantial fraction of mothers (of children below age three) works without using any paid child care. This gap cannot be explained by the usage of nannies or alike as those arrangements are already included in paid child care enrollment. Note that this also holds in the

\footnotetext{
${ }^{1}$ The exact definition of child care enrollment in OECD (2007) for children aged zero comprises formal child care arrangements such as group care in child care centers, registered child minders based in their homes looking after one or more children, and care provided by a carer at the home of the child. For children aged three to five enrollment rates concern formal pre-school services including daycare facilities and in some countries primary schooling. The information in OECD (2007) only refers to the extensive margin of maternal labor force participation and paid child care enrollment. In the subsequent analysis I also consider the intensive margin.
} 
Figure 1: Child Care Enrollment of Children Aged 0 to 2 in the EU
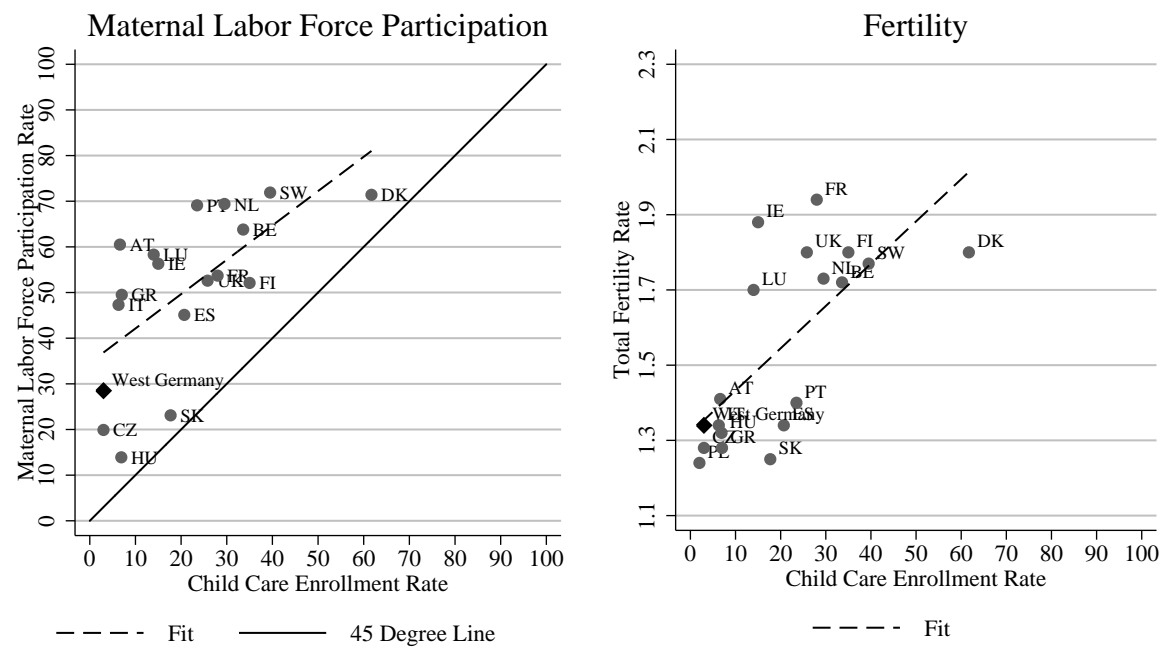

Source: OECD (2007), own calculations

Figure 2: Child Care Enrollment of Children Aged 3 to 5 in the EU
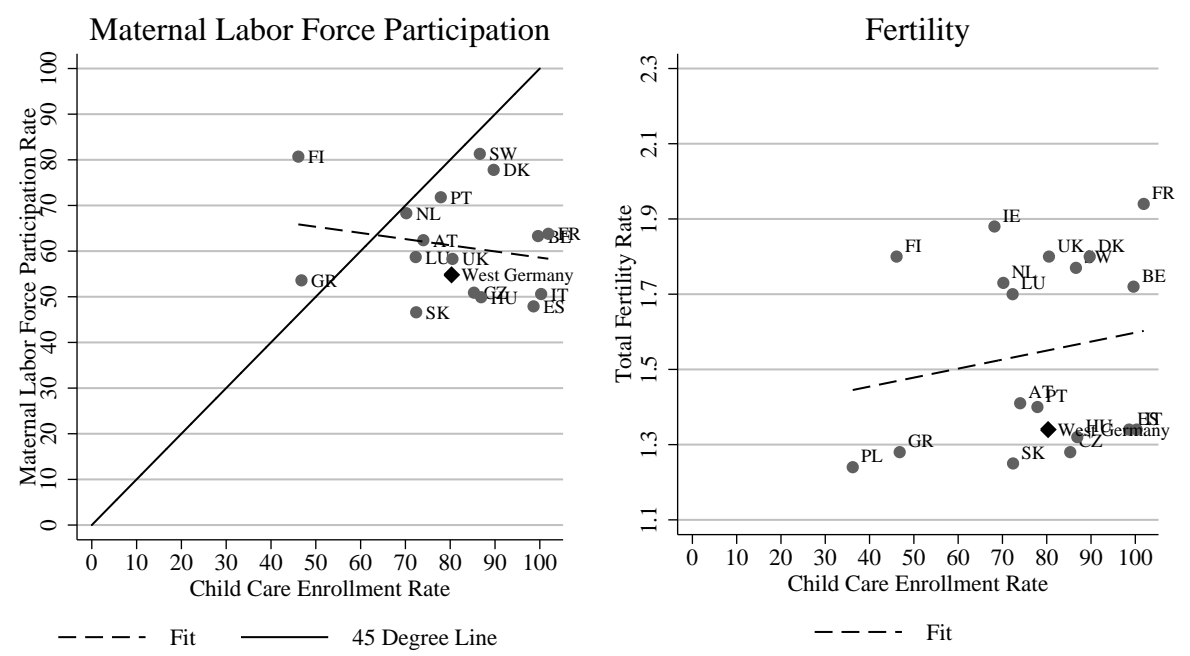

Source: OECD (2007), own calculations 
US and Canada: 18.5 and 39.7 percentage points, respectively, more of the mothers with children aged zero to two are working than using paid child care, see OECD (2007).

The observation that unpaid child care is a common choice has already been acknowledged in one of the earliest economic studies of child care by Heckman (1974) but has been ignored in many recent analyses. Blau and Currie (2006) summarize the results for a wide range of studies for the US (Table 5 in there) which employ static discrete choice models to investigate the interaction between child care and maternal labor force participation. Among those, only three, Ribar (1995), Blau and Hagy (1998), and Tekin (2007) include non-paid, non-maternal child care as choice. However, Blau (2003) shows that the assumption that paid care is always the relevant non-maternal child care option leads to inconsistent preference parameter estimates which as a consequence impacts the result of any counterfactual policy analysis. Recent dynamic models on female labor supply with a focus on paid child care, e.g. Attanasio, Low, and Sanchez-Marcos (2008), Domeij and Klein (2010), Fehr and Ujhelyiova (2010), and Haan and Wrohlich (2011), are as well prone to this critique as all assume that each hour of maternal work requires one hour of paid child care.

The first contribution of this paper is to introduce non-paid, non-maternal child care into a dynamic setting which features returns to experience. All previous studies allowing for non-paid, nonmaternal child care only consider a static framework. Second, by distinguishing paid child care between publicly (subsidized) and market (non-subsidized) provided arrangements the setup allows me to address the policy question asked at the beginning, namely in how far governments can influence maternal labor force participation by increasing the provision of (subsidized) child care. Finally, this question is extended to fertility by making it as well a choice variable. ${ }^{2}$

The analysis is undertaken with a quantitative, dynamic life-cycle model which is calibrated to a sample of West German married females. ${ }^{3}$ West Germany constitutes an ideal candidate for the following reasons. First, in terms of data availability, the German Socioeconomic Panel (GSOEP) is the only European household panel with continuous information on paid child care usage along the extensive and intensive (part- vs. full-time) margin. Moreover, the characteristics of the German child care market permit to infer from the GSOEP whether a child attends publicly (subsidized) or market (non-subsidized) provided child care. In addition, the number of subsidized child care slots per hundred children is available from the German Statistical Office. Second, the low maternal labor force participation, child care enrollment and fertility rates in Germany are representative for Continental Europe (with the exception of France and BeNeLux), such that the results from counterfactual policy experiments should be of interest to other Continental European countries.

The paper contributes to the literature that uses dynamic life-cycle models to evaluate family poli-

\footnotetext{
${ }^{2}$ Fehr and Ujhelyiova (2010), and Haan and Wrohlich (2011) also endogenize fertility but, as already noted, ignore the option of non-paid, non-maternal child care which in turn leads to inconsistent preference parameter estimates, see Blau (2003). Del Boca (2002), and Del Boca and Sauer (2009) constitute a special case. They investigate the impact of child care provision as an "economy-wide factor" on fertility and maternal labor force participation without modeling child care as a choice or as a requirement for working mothers. Blau and Robins (1989), Blau and Robins (1991) for the US, Kravdal (1996) for Norway and Hank and Kreyenfeld (2003) for Germany conduct a reduced form analysis of the role of child care for fertility and partly maternal labor force participation. Lehrer and Kawasaki (1985) and Mason and Kuhlthau (1992) investigate in how fare child care affects birth intensions.

${ }^{3}$ I restrict the analysis to West Germany since, originating from the pre-reunification period, maternal labor force participation and child care enrollment rates differ even today strongly between West and East Germany. In a companion paper Bick (2011) I document these differences in detail and analyze them with the model presented here.
} 
cies, as e.g. in Guner and Knowles (2009) and Erosa, Fuster, and Restuccia (2010), by evaluating a reform that aims at implementing the target for the provision of child care for children aged zero to two set by the European Council at the 2002 Barcelona meeting. Under this reform all working females are granted access to subsidized child care. Such a reform has been implemented in Germany in October 2010. According to my results the lack of subsidized child care constitutes indeed for some females a barrier to participate in the labor market and depresses fertility. The predicted increase of the maternal labor force participation rate is $23 \%$ ( 7.4 percentage points) for mothers with children aged zero to two. This response is very close to the empirically estimates by Baker, Gruber, and Milligan (2008) and Lefebvre and Merrigan (2008) for the late 1990s in Quebec after the introduction of a similar policy. Moreover, the implied price elasticity of maternal labor force participation with respect to paid child care is exactly in the range of estimates listed in Blau and Currie (2006) for the models that feature as well a non-paid, non-maternal child care choice, whereas models that require each hour of maternal labor supply to be backed by one hour of paid child care are associated with much higher price elasticities (in absolute terms). The child care enrollment rate under the new policy is $41 \%$ and thus "overshoots" the targeted level of $33 \%$ while the effect on fertility is only modest, plus $3 \%$ or 0.05 children per female. Nevertheless it is important to endogenize fertility. Women that did not have children prior to the reform but do so afterwards also tend to decrease their labor supply which reduces the aggregate effect on female labor supply, i.e. of all women and not only mothers, compared to a scenario where fertility choices cannot respond to the new environment. This also transpires to the estimated costs of the reform which are substantially underestimated in the latter case.

I consider a further reform which is a natural extension of the previous reform and grants access to subsidized part-time child care for all children aged zero to two, i.e. unconditional on the maternal labor force status. This reform results in a higher child care enrollment rate but has neither an impact on maternal labor force participation nor on fertility relative to the first reform. Hence, only females that are constrained in their labor force participation choice by the lack of subsidized child care are also constrained in their fertility choice.

The structure of the paper is as follows: In Section 2, I describe the data set, and how the sample is selected and constructed. Section 3 documents facts about maternal labor force participation, child care usage and the supply of subsidized child care in West Germany. I introduce the model in Section 4, discuss the calibration in Section 5 and the model evaluation in Section 6. Section 7 presents the results from a set of counterfactual policy experiments and Section 8 concludes.

\section{Data}

The analysis in this paper is based on the German Socioeconomic Panel (GSOEP), an annual household panel comparable in scope to the American PSID. ${ }^{4}$ The GSOEP provides all information required for the pursued question, i.e. female cohabitation, labor force participation and birth histories, child care enrollment choices, paid child care fees, and income. In particular, it is the only European household panel with information on paid child care usage along the extensive and

\footnotetext{
${ }^{4}$ A detailed description of the GSOEP can be found in Wagner, Frick, and Schupp (2007).
} 
Figure 3: A Child's Life from Birth to Adulthood

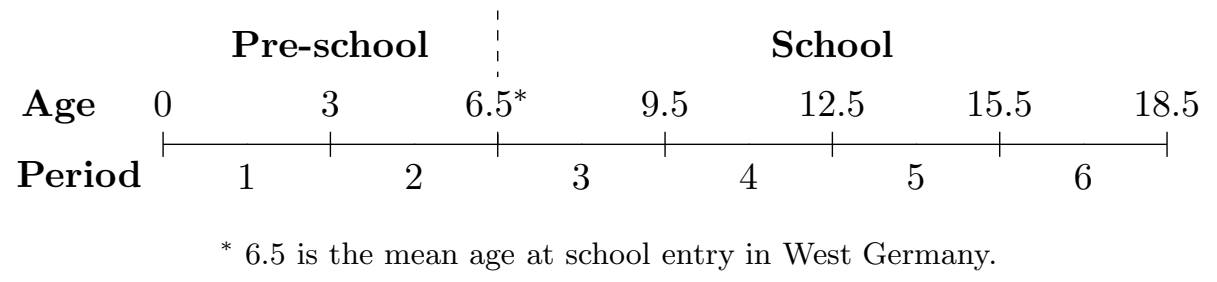

intensive (part- vs. full-time) margin over the entire sample period. ${ }^{5}$ The data are drawn from the first wave in 1984 through 2007 spanning the years 1983 to 2006 since the variables on labor force participation and income refer to the year prior to each interview.

Following the common practice in the literature on female labor supply and fertility, see e.g. Francesconi (2002), only females living in a continuous relationship (marriage or cohabitation) with the same partner are included in the sample. ${ }^{6}$ I include only the most recent relationship but require that it is still intact at the last interview and that all children (if present) are from the current partner. The analysis focuses entirely on West German females and consequently only females that lived there throughout the whole observation period are considered. Finally, given a trade-off between sample size and potential cohort effects females born between 1955 and 1975 are included. The number of individuals satisfying the respective selection criteria are shown in Table A.1 in Appendix A.1.

Maternal labor force participation and child care enrollment choices by the children's age constitute the core of the analysis in this paper. Similarly to Apps and Rees (2005), my focus is however not on the maternal labor force participation status in each month of a child's life but during the different stages of a child's adolescence. The split of pre-school ages in the two periods "zero to two" and "three to mandatory school age" matches the reported time categories for the aggregate statistics on the provision of publicly provided child care, see further below. It further provides a natural division into two distinctive development stages of pre-school children, although the exact cut-off may be disputable. To keep the remaining periods at a similar length, the subsequent age brackets cover three years until adulthood is reached. Figure 3 summarizes this mapping. Table 1 presents the final number of observations for each period grouped by the current number of children, e.g. the sample contains 458 females with currently two children and the youngest child being younger than three. Given the low number of observations for females with currently four and more children, the analysis on maternal labor force participation and child care enrollment in this paper focuses on females with one to three children only. ${ }^{7}$

For each period the female labor supply is constructed similar to Francesconi (2002): I assign 0 to

\footnotetext{
${ }^{5}$ The European Statistics on Income and Living Conditions (EU-SILC) also has detailed information on child care usage but started only in 2004.

${ }^{6}$ The implied selection bias of focussing on this group of females may go in opposite directions. For example, the unobservables that produce long-term relationships could make women more desirable in the labor market (e.g., good communication and conflict management skills) but could also reflect preferences for non-market activities as household production. A more detailed discussion can be found in Francesconi (2002).

${ }^{7}$ Merging the $4+$ children observations with the 3 children into one category $(3+)$ observations does not affect the presented facts.
} 
Table 1: Observations

\begin{tabular}{ccccc} 
& Current Nr. of Children \\
Age Youngest Child & $\mathbf{1}$ & $\mathbf{2}$ & $\mathbf{3}$ & $\mathbf{4}+$ \\
\hline$<\mathbf{3}$ & 400 & 458 & 126 & 39 \\
$<\mathbf{6 . 5}$ & 186 & 332 & 99 & 27 \\
$<\mathbf{9 . 5}$ & 131 & 274 & 85 & 30 \\
$<\mathbf{1 2 . 5}$ & 111 & 212 & 59 & 15 \\
$<\mathbf{1 5 . 5}$ & 86 & 129 & 38 & 8 \\
$<\mathbf{1 8 . 5}$ & 64 & 106 & 22 & 8
\end{tabular}

Note: To avoid biased means if there are trends in labor participation or child care enrollment within a period, i.e. during a stage of a child's adolescence, only periods that are neither interrupted by another birth nor left or right censored through the first or last interview are included.

each month in which the female does not work, 0.5 to each month in which she works part-time and 1 to each month in which she works full-time. ${ }^{8}$ The period labor force participation status is then defined by the mean over all months. Period means below 0.25 correspond to not working, between 0.25 and 0.75 to part-time working, and above 0.75 to full-time working. As an implication, a female working part-time in each month of a period and one not working in the first half of a period but full-time in the second half have the same period labor force participation status, namely part-time working. In line with the objective of this paper this definition reflects how much a female has worked in total during certain stages of her children's adolescence.

The GSOEP asks for enrollment in paid child care, distinguishing between two different categories, namely daycare centers and nannies, and whether the child is enrolled part- (during the morning or afternoon) or full-time (all day). Since virtually all daycare centers receive public subsidies I use this category for publicly provided child care, henceforth called subsidized child care. During the observation period parents could claim only in special circumstances, e.g. severe diseases, financial support for hiring a nanny reflecting that nannies rather constitute a market arrangement. Accordingly, I label them as non-subsidized child care. The corresponding period enrollment status for subsidized and non-subsidized child care is then calculated in the same way as the labor force participation status. ${ }^{9}$ Finally, aggregate statistics on the provision of subsidized part- and full-time child care by age groups (zero to two and three to six and a half) are available from the Germans Statistical Office. ${ }^{10}$

\footnotetext{
${ }^{8}$ The monthly labor force participation status is based on the retrospective information for the year prior to each interview. For the classification of part- and full-time work in each month I follow the convention outlined in the GSOEP documentation (http://www.diw.de/documents/dokumentenarchiv/17/60055/pgen.pdf).

${ }^{9}$ The child care enrollment status is only known for the interview month. In Appendix A.2 I discuss the imputation for the remaining months and outline how I deal with changes in the GSOEP child care questions over time.

${ }^{10}$ In Appendix A.3 I describe how I calculate the period provision rates of subsidized child care such that they are consistent with the definition of the period labor force participation and child care enrollment status as discussed
} 
Figure 4: Maternal Labor Force Participation and Child Care

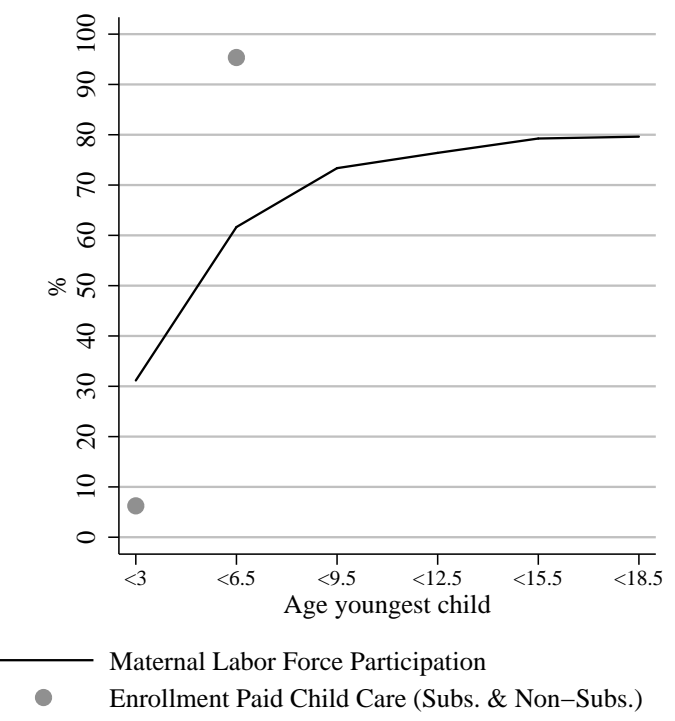

\section{Stylized Facts}

This section documents labor force participation and child care enrollment choices for the selected sample of West German married females. ${ }^{11}$ These facts will be either used as calibration targets for the model developed in Section 4 or for the evaluation of the model fit. I further describe features of the German child care market, namely the provision of subsidized child care as well as the parental fees for subsidized and non-subsidized child care, that can be considered as exogenous for the individual choices and will serve as model inputs.

I start with the discussion of the total maternal labor force participation and child care enrollment rates and will turn to the part- and full-time differences further below.

\subsection{Maternal Labor Force Participation and Child Care}

Figure 4 shows that the maternal labor force participation rate increases with the youngest child's age but at a strongly decreasing rate. In particular, the major increase happens during pre-school ages (from $31 \%$ to $61 \%$ ) and at school entry (from $61 \%$ to $73 \%$ ). The subsequent increases are far smaller and when the youngest child turns adult (ages 16 to 18.5) 80\% of the mothers in the sample are working. The increase of the child care enrollment rate, comprising subsidized and nonsubsidized child care, from $6 \%$ for children aged zero to two to $95 \%$ for children aged three to six and a half is much larger than the corresponding increase in the maternal labor force participation

before.

${ }^{11}$ Since the fraction of females with one, two and three children varies by the youngest child's age, see Table 1 , I weight the corresponding labor force participation and child care enrollment rates by the fraction of females in the sample with one, two and three children (conditional on having children) which are given in Table 4. This adjustment has only a small quantitative but no qualitative impact on the presented facts. 
Table 2: Child Care Enrollment Conditional on Maternal Labor Force Participation Status

Ages 0 to $2 \quad$ Ages 3 to 6.5

\section{At least part-time care}

$\begin{array}{lcc}\text { Not Working } & 2.9 & 93.2 \\ \text { Working } & 13.7 & 96.7\end{array}$

Table 3: Child Care Enrollment and Provision

Ages 0 to $2 \quad$ Ages 3 to 6.5

\begin{tabular}{lcc} 
Enrollment Paid Child Care (Subs. \& Non-Subs.) & 6.2 & 95.4 \\
$\quad$ Enrollment Non-Subsidized Child Care & 40.4 & 0.8 \\
\hline $\begin{array}{l}\text { Enrollment Paid Child Care (Subs. \& Non-Subs.) } \\
\text { Provision Subsidized Child Care }\end{array}$ & 6.1 & 95.6
\end{tabular}

rate. Accordingly, the selected sample displays a similar relationship as the cross-section of EU countries shown in Figures 1 and 2: the maternal labor force participation rate for the age group zero to two is much larger than the enrollment rate in paid child care $(31 \%$ vs. $6 \%)$, whereas the opposite is true for the age group three to six and a half (61\% vs. $95 \%)$.

Table 2 takes a closer look at this relationship. Only 13.7\% of the working mothers whose youngest child is of age zero to two use paid child care. Given the age of the children the remaining $86.3 \%$ of the working mothers necessarily use some form of non-paid, non-maternal child care to free up the time to work. Although $95 \%$ of the husbands are working full-time, they could still take care of the children if the females work at another time of the day than their husbands. Grandparents, other family members or friends might also take care of the children at no monetary costs. Since the total enrollment rate in paid child care is $95 \%$ for children aged three to six and a half, it is not surprising that the respective conditional child care enrollment rates hardly vary with the maternal labor force participation status. Overall, the correlation between the maternal labor force participation and child care enrollment rate is weak whereas the correlation of both variables, particularly the child care enrollment rate, with the youngest child's age is large.

Table 3 shows that non-subsidized child care is an important source of paid child care in relative terms for children aged zero to two: among the children in this age group enrolled in paid child care, $40.4 \%$ are enrolled in non-subsidized child care, either exclusively or in addition to subsidized child care. However, in absolute terms this is still negligible (amounting to $2.5 \%$ of all children aged zero to two). For children aged three to six and half non-subsidized child care is hardly used independent of whether measured in relative or in absolute terms. This latter result is not surprising as the fees for non-subsidized child care are three to four times as expensive as subsidized child care (see Table 
Figure 5: Maternal Labor Force Participation and Child Care: Part- vs. Full-time
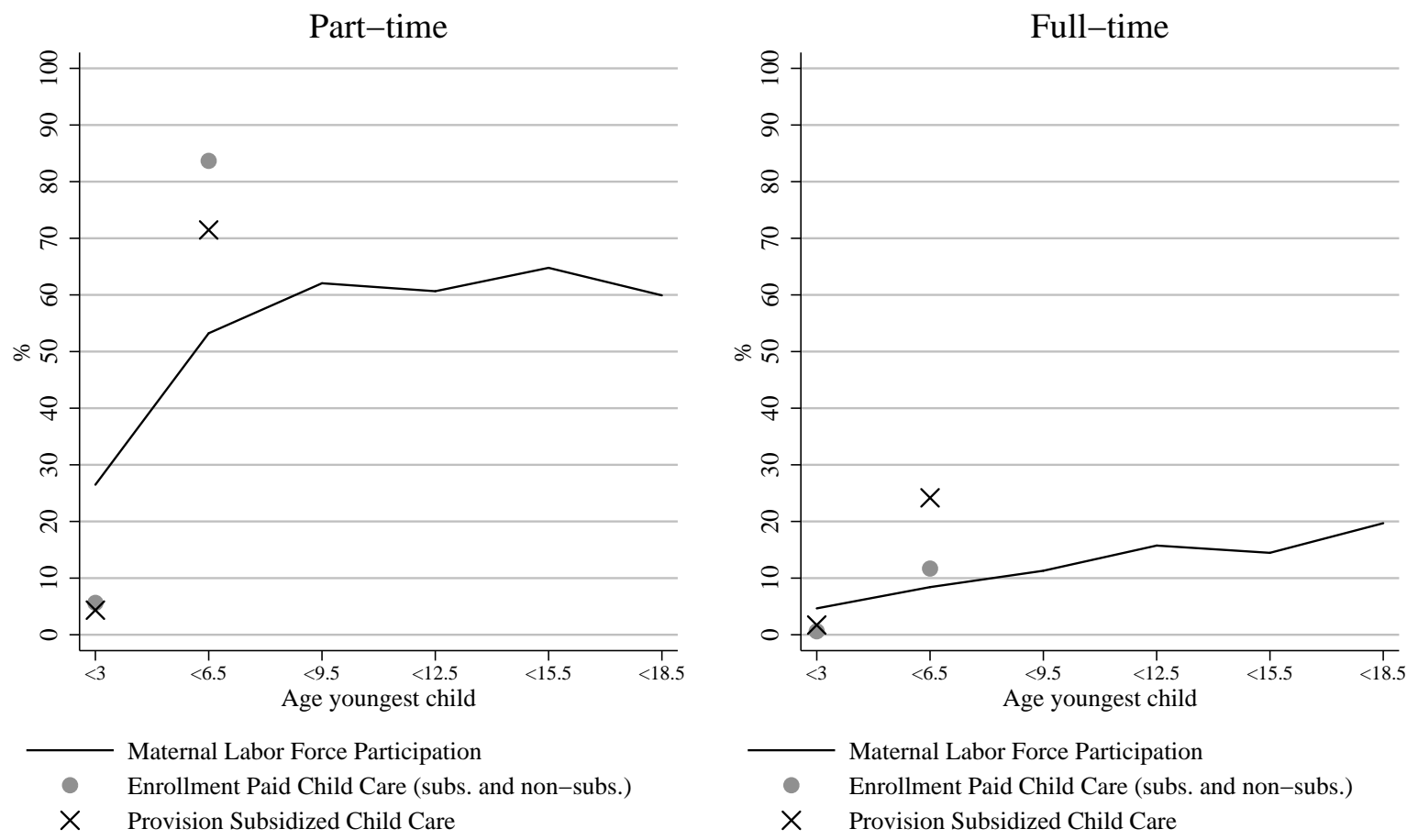

C.6 in Appendix C.3) and, as shown in the third row of Table 3, subsidized child care is available for nearly all children in that age group. In contrast, only for $6.1 \%$ of the children aged zero to two a subsidized child care slot is available.

The huge disparity of the provision rates between the two age groups stems from the historical objective to subsidize child care in Germany, namely to offer affordable, high quality pre-school education for children from age three onwards, see Kreyenfeld, Spieß, and Wagner (2002). Wrohlich (2008) documents a substantial excess demand for subsidized child care for children aged zero to two suggesting that a sizeable fraction of mothers is rationed in their choice of the paid child care mode as they do not have access to subsidized child care. Hence, the fact that for children aged zero to two the provision rate exceeds the actual enrollment in subsidized child care (given that a substantial fraction is enrolled in non-subsidized child care) should therefore rather be interpreted as a mismatch of supply and demand of subsidized slots than as an excess supply.

\section{$3.2 \quad$ Part- vs. Full-time}

Another important feature of the data is the prevalence of part-time maternal labor force participation, part-time enrollment in paid child care (again, subsidized and non-subsidized) and provision of part-time subsidized child care, see Figure 5. The profile of the total maternal labor force participation rate follows the profile of the part-time maternal labor force participation rate until age nine and a half, while the increase afterwards mainly stems from the full-time labor force participation 
rate. Although the full-time child care enrollment for children aged three to six and a half is above the corresponding full-time maternal labor force participation rate, the usage of non-paid child care is still pervasive among full-time working mothers in this age group. Only $32.4 \%$ of them actually use full-time child care. About three fourth of the subsidized child care slots are part-time with the actual enrollment rates in part-time child care being even higher because some full-time slots are only used part-time. It is important to these facts are neither an artifact of distinguishing only by part- and full-time labor force participation nor of the aggregation of the monthly to the period statuses. In particular, the results are not driven by mothers working very few hours. Conditional on working, only $15.6 \%(10.6 \%)$ of those whose youngest child is of age zero to two (three to six and a half) are working less than 10 hours per week. ${ }^{12}$

\subsection{Summary Key Facts}

The facts documented in this section about labor force participation of married West German females with children and their child care enrollment decisions can be summarized as follows:

1. The maternal labor force participation rate grows as the children age but at a strongly decreasing rate.

2. Many non-working females use paid child care and many working females do not use paid child care.

3. Non-subsidized child care is only important for children aged zero to two but only in relative terms.

4. While subsidized child care is three to four times as cheap as non-subsidized child care, it is only provided for very few children aged zero to two. Although for nearly all children aged three to six and a half a subsidized child care slot is available, the majority of those slots is only part-time.

5. For both, child care enrollment and maternal labor force participation, the part-time rates exceed the full-time rates.

In the next section, I develop a life-cycle model to explain the set of presented facts on maternal labor force participation and child care enrollment taken as given the supply of subsidized child care slots and parental fees for subsidized and non-subsidized child care.

\section{The Model}

This section introduces a stylized life-cycle model for married females featuring fertility, labor force participation and child care choices.

\footnotetext{
${ }^{12}$ The hours worked are only available for the interview months. More detailed results are available upon request.
} 


\subsection{Demographics}

A female lives for six periods, each of three year length, reflecting the distinctive stages of a child's adolescence, as shown in Figure $3 .{ }^{13}$ At the beginning of her life she is exogenously matched with a man and then chooses how many children to have. Both the husband and the children stay with her throughout her whole life. If a female chooses to have more than one child, all children are born as multiples. This simplifying assumptions avoids to keep track of the mother's age at first and every subsequent birth or alternatively the age distribution of children at a given mother's age. As a consequence, the model is not suitable to study the interactions between child care and the spacing and timing of birth.

\subsection{Endowments}

Females and their husbands are indexed by income shocks $\epsilon$ and $\epsilon^{*}$ which determine the stochastic component of their market incomes. Asterisks refer to parameters for the husband. Both spouses are assigned initial income shocks $\left(\epsilon_{1}, \epsilon_{1}^{*}\right)$ in period one which subsequently evolve stochastically over time according to an $\mathrm{AR}(1)$ process:

$$
\begin{aligned}
\epsilon_{t} & =\rho \epsilon_{t-1}+\varepsilon_{t} \text { with } \varepsilon_{t} \sim N\left(0, \sigma_{\varepsilon}^{2}\right) \\
\epsilon_{t}^{*} & =\rho^{*} \epsilon_{t-1}^{*}+\varepsilon_{t}^{*} \text { with } \varepsilon_{t}^{*} \sim N\left(0, \sigma_{\varepsilon^{*}}^{2}\right)
\end{aligned}
$$

In the first two periods while children are not yet in school, females can enroll them in subsidized and/or non-subsidized child care. Both types of child care are perfect substitutes with the exception of the price and availability. In contrast to non-subsidized child care, I assume as in Wrohlich (2006) and Haan and Wrohlich (2011) that access to subsidized child care slots, denoted as $a_{t}$, is rationed and randomly assigned to mothers by a lottery with age-dependent success probabilities. These success probabilities are assumed to be independent of the maternal labor force participation status or number of children as their is no information in the data that would allow me to identify such dependencies.

\subsection{Preferences}

The female is assumed to be the household's sole decision maker, i.e. she has the full bargaining power. A childless woman $(n=0)$ receives utility from her share of household consumption $\left(\psi(n) c_{t}\right)$ and leisure which is the time endowment of one less time worked in the market $l_{t}$ :

$$
u_{t, n=0}=\frac{\left(\psi(n) c_{t}\right)^{1-\gamma_{0}}-1}{1-\gamma_{0}}+\delta_{1} \frac{\left(1-l_{t}\right)^{1-\gamma_{1}}-1}{1-\gamma_{1}}
$$

Household consumption $\left(c_{t}\right)$ is transformed into the consumption realized by an adult, the female's share, using the OECD equivalence scale:

$$
\psi(n)=\frac{1}{1.7+0.5 n} .
$$

\footnotetext{
${ }^{13}$ For period two the overlap is not exact since the mean duration in the data is three and a half years.
} 
The utility function for a mother $(n>0)$ is different. Her leisure is further reduced by the time caring for her children $\left(m_{t}\right)$ while she receives in addition utility from having children $(\mathbf{N})$ and child quality $\left(\mathbf{Q}_{t}\right)$ :

$$
u_{t, n>0}=\frac{\left(\psi(n) c_{t}\right)^{1-\gamma_{0}}-1}{1-\gamma_{0}}+\delta_{1} \frac{\left(1-l_{t}-m_{t}\right)^{1-\gamma_{1}}-1}{1-\gamma_{1}}+\delta_{2} \mathbf{N}+\delta_{3} \mathbf{Q}_{t}
$$

where $\delta_{i} \forall i=1,2,3$ measure the contribution of each part to total utility relative to the utility from consumption. This general specification is relatively standard, see e.g. Greenwood, Guner, and Knowles (2003) or Jones, Schoonbroodt, and Tertilt (2001). Let me now explain the details of the two additional parts. The utility from having $n>0$ children is

$$
\mathbf{N}=\frac{(1+n)^{1-\gamma_{2}}-1}{1-\gamma_{2}}-\zeta
$$

The first component governs both the utility from having the first child and the increase in utility from each additional child, while the second component shifts the utility from having children but not does not affect how much utility increases from each additional child after the first one. Put differently, it only affects the $n=0$ vs. $n=1$ choice but not any other decision conditional on having children. Anticipating the calibration results, this additional degree of freedom is needed to generate the empirically observed fraction of childless females, see Table 4 further below. ${ }^{14}$ This is also possible with a sufficiently low value of the utility weight $\delta_{2}$, in which case however the marginal utility from having another child becomes as well very small such that the fertility distribution, i.e. the fraction of females with $n=1, n=2$ and $n=3$, cannot be matched any longer. While it may be tempting to seek an economic interpretation for $\zeta$, the parameter simply complements the properties of the functional form assumption $\frac{(1+n)^{1-\gamma_{2}}-1}{1-\gamma_{2}}$ (a large marginal utility of the first child) in order to generate a fertility distribution consistent with the data.

The child quality term $\mathbf{Q}_{t}$ introduces the main behavioral trade-offs. The concrete specification is motivated by the facts outlined in Section 3 and similar to Ribar (1995). Children have, similar to their mothers, a time constraint:

$$
m_{t}+c c_{s, t}+c c_{n s, t}+c c_{n p, t}=1
$$

They either spend time with their mother $\left(m_{t}\right)$, are taken care of in a paid child care arrangement, either subsidized $\left(c c_{s, t}\right)$ or non-subsidized $\left(c c_{s, t}\right)$, or in a non-paid child care arrangement $\left(c c_{n p, t}\right)$. These inputs affect child quality $\mathbf{Q}_{t}$ in the following way:

$$
\mathbf{Q}_{t}=\xi(t) m_{t}^{\gamma_{3}}-\phi(t) c c_{n p, t}^{\phi_{2}}=\xi(t) m_{t}^{\gamma_{3}}-\phi(t)\left(1-m_{t}-c c_{s, t}-c c_{n s, t}\right)^{\phi_{2}}
$$

Note that both types of paid child care, i.e. subsidized and non-subsidized, are perfect substitutes

\footnotetext{
${ }^{14}$ Greenwood, Guner, and Knowles (2003) employ a very similar utility function without $\zeta$ and their model predicts no childless females. Their setup features a time cost of having children that in principle may prevent (some) women from having children at all. The calibrated time costs are however too low to generate such an outcome quantitatively. I experimented with a version without $\zeta$ but such a time cost. In order to match the fraction of females without children the time costs would have to be much larger than in Greenwood, Guner, and Knowles (2003) with the counterfactual implication that essentially no mother would be willing to work full-time.
} 
with the exception of the price and availability. As in Ribar (1995), the effect of paid child care to overall child quality is ambiguous and depends only on the quality of paid care relative to maternal and non-paid care. Specifically, I assume that child quality is increasing in maternal time spend with the children $m_{t}$ and decreasing in the usage of non-paid child care. ${ }^{15}$ This latter mechanism is needed to explain usage of paid child care (which reduces resources for consumption) while nonpaid child care is available, see also Blau and Hagy (1998), Wrohlich (2006) and Tekin (2007). ${ }^{16}$ Thus, the above setup does not require that for each unit of labor supply one unit of paid child care has to be bought since instead non-paid child care could be used. Without this assumption the documented fact that not all working females use paid child care, compare Table 2, could not be generated. Possible interpretations for the utility costs of non-paid child care could be that nonpaid child care arrangements provide lower quality child care than paid child care arrangements or mothers, the effort to organize care provided by grandparents, other family members or friends, the foregone joint leisure-time with the husband if he takes care of the children or the disutility of taking care of the children while working from home (e.g. as self-employed). Still there is no reason to believe that families actually have direct negative preferences regarding unpaid care, but the approach is a flexible way to proxy for the direct costs of non-paid care, see Ribar (1995). This discussion also reveals that it would be too far stretched to interpret $\mathbf{Q}_{t}$ as children's human capital which is also not done by Ribar (1995), Blau and Hagy (1998), Wrohlich (2006) and Tekin (2007). For a recent structural approach to estimate the effect of employment and child care decisions of married mothers on children's cognitive development, see e.g. Bernal (2008).

Hotz and Miller (1988) assume that mothers incur a time cost of having children that declines geometrically with the age of the children to capture that children of different ages have different needs. I abstract from such time costs but assume in turn that the utility mothers receive from spending time with their children may decline geometrically over time, i.e. as the children get older. This increases both the incentive to use (more) paid and non-paid child care, which would not be captured by a fixed time cost, and to participate (more) in the labor market as the children get older. The speed of the reduction is given by the parameter $\xi_{1}>0$ whereas the lower bound, i.e. the utility in the last period when children are of age 15.5 to 18.5 , is governed by $\xi_{2} \in[0,1]$ through the following linear transformation:

$$
\xi(t)=\xi_{2}+\frac{t^{-\xi_{1}}-T^{-\xi_{1}}}{1-T^{-\xi_{1}}}\left(1-\xi_{2}\right) \text { for } t=1, \ldots, T \text { and } T=6 .
$$

With the focus being on pre-school child care, I assume that mother do not incur any utility costs of using non-paid child care once children enter school, i.e.

$$
\phi(t)=\left\{\begin{array}{cl}
\phi_{1} & \text { for } t \leq 2 \\
0 & \text { else. }
\end{array}\right.
$$

This implies that no mother would use paid after school child care which is line with the data: only

\footnotetext{
${ }^{15}$ Ribar (1995) specifies his estimated model the other way around than Equation (7), i.e. he includes paid child care usage instead of non-paid child care usage in the utility function. Since the three modes of care, paid, non-paid and maternal are linked through the time constraint (6) this should not affect the results.

${ }^{16}$ Blau and Hagy (1998) and Tekin (2007) allow for observed and unobserved quality differences even within one child care mode. Tekin (2007) assumes that only employed mothers use paid child care which is however at odds with the data, see Table 2.
} 
$4.5 \%$ of the children aged six to 12.5 in the sample are enrolled in paid after school care. Hereby it is important to mention that children in this age group in West Germany usually attend school only part-time, i.e. during the morning. As in Ribar (1995), Blau and Hagy (1998), Wrohlich (2006) and Tekin (2007), I assume that every female can use as much non-paid child care as she desires. ${ }^{17}$

\subsection{Budget Constraint}

The per-period budget constraint is given by:

$$
c_{t}=\tau\left[y_{t}\left(l_{t}, x_{t}, \epsilon_{t}\right), y_{t}^{*}\left(t, \epsilon_{t}^{*}\right)\right]-f_{c c}\left[n, t, c c_{s, t}, c c_{n s, t}, y_{t}, y_{t}^{*}\right]+\Upsilon\left[n, t, l_{t}\right] .
$$

The function $\tau$ calculates the after tax household income from the female's $\left(y_{t}\right)$ and husband's $\left(y_{t}^{*}\right)$ gross income. The latter depends on two components: a deterministic component in time $t$, i.e. all husbands are assumed to work full-time and thus accumulate full-time experience, ${ }^{18}$ and a stochastic component represented by the husband's current period income shock $\left(\epsilon_{t}^{*}\right)$. In contrast, the female's income depends on her labor supply $\left(l_{t}\right)$, accumulated experience $\left(x_{t}\right)$ through past labor force participation

$$
x_{t}=x_{t-1}+l_{t-1}, \text { with } x_{1}=0
$$

and her current period income shock $\left(\epsilon_{t}\right)$. Similar to the vast majority of structural models investigating labor supply and fertility choices of married females, see e.g. Hotz and Miller (1988), Francesconi (2002) or Haan and Wrohlich (2011), I abstract from savings. Child care fees $f_{c c}$ depend on the number $(n)$ and age $(t)$ of the children, the utilized amount of subsidized $\left(c c_{s, t}\right)$ and non-subsidized $\left(c c_{n s, t}\right)$ child care as well as the gross household income. In addition, households receive transfers $\Upsilon$ conditional on the time period/age of the children $(t)$ and choices $\left(n, l_{t}\right)$. The functional forms for the gross incomes $y$ and $y^{*}$, the tax schedule $\tau$, the child care fees $f_{c c}$ and transfers $\Upsilon$ are specified further below in Section 5.1.

\subsection{Choice Variables}

All choices are assumed to be discrete. Labor supply $l_{t}$ can take on three values:

$$
l_{t}= \begin{cases}0 & \text { for non-working } \\ \frac{1}{4} & \text { for part-time work } \forall t=1, \ldots, 6 . \\ \frac{1}{2} & \text { for full-time work }\end{cases}
$$

If the (non-sleeping) time endowment would be 16 hours, then part-time labor force participation would correspond to four and full-time work to eight hours. Similarly, subsidized $c c_{s, t}$ and non-

\footnotetext{
${ }^{17}$ Given that in the data essentially all husbands are working full-time, the children's grandparents, i.e. the female's or husband's parents, are the most likely provider of non-paid child care such that the geographical distance towards grandparents is probably one of the most important sources for heterogeneity in access to non-paid child care. Table B.1 in Appendix B shows that this heterogeneity does hardly translate in any statistically significant differences of the maternal labor force participation and child care enrollment rates. Although this is not a proof for an unconstrained access to non-paid child care, it is clearly not a rejection of the assumption.

${ }^{18}$ In the data, $95 \%$ of all husbands in the selected sample work full-time.
} 
subsidized child care $c c_{n s, t}$ can take on three values:

$$
c c_{i, t}= \begin{cases}0 & \text { for no paid child care } \\ \frac{1}{4} & \text { for paid part-time child care } \forall t=1,2 \text { and } i=s, n s . \\ \frac{1}{2} & \text { for paid full-time child care }\end{cases}
$$

The actual choice of subsidized child care is however restricted by the access $a_{t}$ to a subsidized child care slot:

$$
c c_{s, t} \leq a_{t} \forall t=1,2
$$

with

$$
a_{t}=\left\{\begin{array}{ll}
0 & \text { no access to subsidized child care } \\
\frac{1}{4} & \text { access to subsidized part-time child care } \forall t=1,2 . \\
\frac{1}{2} & \text { access to subsidized full-time child care }
\end{array} \forall\right.
$$

As already mentioned, the access to a subsidized child care slot is determined by a lottery with age- and type-dependent, i.e. part- or full-time, success probabilities. Paid child care in subsidized and non-subsidized arrangements is restricted to

$$
c c_{s, t}+c c_{n s, t} \leq \frac{1}{2} \forall t=1,2
$$

i.e. child care facilities are only open during the first half of the day in the morning and early afternoon. A mother can still spend time with her children in the late afternoon and evening such that in principle

$$
m_{t} \in\left\{0, \frac{1}{4}, \frac{1}{2}, \frac{3}{4}, 1\right\} .
$$

However, while she is working and/or the children are in paid child care or later in life in mandatory costless schooling $\left(s_{t}\right)$, she cannot spend any time with her children:

$$
m_{t} \leq \begin{cases}1-\max \left\{l_{t}, c c_{s, t}+c c_{n s, t}\right\} & \forall t \leq 2 \\ 1-\max \left\{l_{t}, s_{t}\right\} & \forall 3 \leq t \leq 6 .\end{cases}
$$

\subsection{Dynamic Problem}

Figure 6 presents the timing of events during a female's life which is defined by the stages of her children's adolescence (compare also Figure 3). The term $z_{t}$ combines the income shocks of both spouses $\left(\epsilon_{t}, \epsilon_{t}^{*}\right)$ and the female's experience level $\left(x_{t}\right.$, with $\left.x_{1}=0\right)$. The first period is split up in two stages with different state and decision variables. In the first stage, the initial income shocks are assigned and the female chooses the optimal number of children $(n)$ taking into account the uncertainty with respect to the access to subsidized child care:

$$
\max _{n}\left\{E_{a_{1}} V\left(1, \epsilon_{1}, \epsilon_{1}^{*}, x_{1}, n, a_{1}\right), n=0,1,2, \ldots, N\right\},
$$

with $V(\cdot)$ being the female's value function. Once the optimal number of children $(n)$ is chosen, $n$ becomes a state variable as the children stay with the mother throughout her entire life. After 
Figure 6: Life Cycle

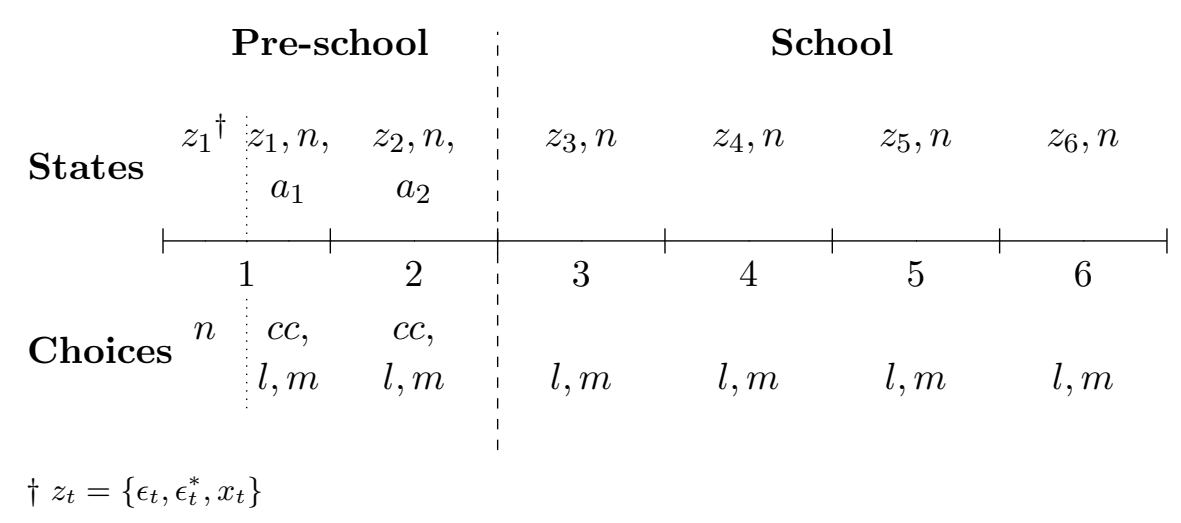

access to subsidized child care is determined by the lottery, the female decides on her labor supply $\left(l_{1}\right)$ and those with children, on how much time to spend with them $\left(m_{1}\right)$ and on their enrollment in subsidized child care $\left(c c_{s, 1}\right)$, possibly restricted by $a_{1}$, and non-subsidized child care $\left(c c_{n s, 1}\right)$. Obviously, childless women only choose their labor supply $l_{t}$ in any given period. The following Bellman equation represents the female's problem in the second stage:

$$
\begin{aligned}
V\left(1, \epsilon_{1}, \epsilon_{1}^{*}, x_{1}, n, a_{1}\right)= & \max _{m, l, c c_{s}, c c_{n s}} u_{1}+\beta E_{\epsilon, \epsilon^{*}, a_{2}} V\left(2, \epsilon_{2}, \epsilon_{2}^{*}, x_{2}, n, a_{2}\right) \\
& \text { subject to (10), (11), (14), (16) and (18). }
\end{aligned}
$$

$u_{1}$ is the period-specific utility function (Equation (4)) and $\beta$ is the discount factor. At the beginning of period two, the new income shocks $\left(\epsilon_{t}, \epsilon_{t}^{*}\right)$ realize according to the $\operatorname{AR}(1)$ process specified in Equation (1) and access to child care $\left(a_{2}\right)$ is drawn from a new lottery. The set of choice variables in period two is identical to the second decision stage in period one and the value function is given by

$$
\begin{aligned}
V\left(2, \epsilon_{2}, \epsilon_{2}^{*}, x_{2}, n, a_{2}\right)= & \max _{m, l, c c_{s}, c c_{n s}} u_{2}+\beta E_{\epsilon, \epsilon^{*}} V\left(3, \epsilon_{3}, \epsilon_{3}^{*}, x_{3}, n, 0\right) \\
& \text { subject to }(10),(11),(14),(16) \text { and (18). }
\end{aligned}
$$

From period three onwards, children attend mandatory school and females cannot use child care anymore $\left(a_{t}=0\right.$ for $t \geq 3$ ). Hence, a female only decides on how much to work and how much time to spend with her children:

$$
\begin{aligned}
V\left(t, \epsilon_{t}, \epsilon_{t}^{*}, x_{t}, n, 0\right)= & \max _{m, l} u_{t}+\beta E_{\epsilon, \epsilon^{*}} V\left(t+1, \epsilon_{t+1}, \epsilon_{t+1}^{*}, x_{t+1}, n, 0\right) \forall 3 \leq t \leq 6 \\
& \text { subject to }(10),(11) \text { and }(18) \\
& \text { and } V(7, \ldots)=0 .
\end{aligned}
$$




\subsection{Maternal Leave}

An important element affecting labor force participation decisions of females with children aged zero to two is the German maternal leave regulation. It permits every mother who worked until the birth of a child to return to her pre-birth employer at her pre-birth wage within three years after birth. Since in the model life starts with the birth decision, there is no pre-birth labor supply and I therefore grant all females the right to go on maternal leave. ${ }^{19}$ Relevant in this setup is the stochastic part of income. By construction, part- and full-time working mothers work at their initial or pre-birth wage income shock in period one. Hence, the maternal leave regulation has only to be modeled explicitly for mothers that do not work in the first period, i.e. for which $l_{1}=0$ or equivalently $x_{2}=0$. I assume that they draw a new income shock at the beginning of the second period according to Equation (1) (e.g. an offer for a new position) but can opt for the pre-birth income shock (e.g. return to the pre-birth position) such that the offered wage in the second period is given by $y_{2}\left(l_{2}, x_{2}=0, \max \left\{\epsilon_{1}, \epsilon_{2}\right\}\right)$. The third period income shock is then determined by

$$
\epsilon_{3}= \begin{cases}\rho \max \left\{\epsilon_{1}, \epsilon_{2}\right\}+\varepsilon_{3} & \text { if } n>0, l_{1}=0, l_{2}>0 \\ \rho \epsilon_{2}+\varepsilon_{3} & \text { else. }\end{cases}
$$

\section{Calibration}

In the following paragraphs, I specify the functional forms for the exogenous model inputs which are, where applicable, either presented as monthly or annual values. In the model all variables are transformed appropriately to align with the model period's length of three years. All monetary values are expressed in real terms in $2008 €$. In this section I further discuss the target moments for the calibration exercise and the calibrated preference parameters.

\subsection{Functional Forms}

\subsubsection{Income}

Husbands In line with the data, all husbands are assumed to work full-time and thus accumulate full-time experience. I assume that the log of their gross income $y_{t}^{*}$ is a concave function of experience and hence of time in the model or, respectively, of the youngest child's age in the data:

$$
\ln y_{t}^{*}=\eta_{0}^{*}+\eta_{1}^{*}(t-1)+\eta_{2}^{*}(t-1)^{2}+\epsilon_{t}^{*}
$$

The gross full-time income $y_{t}\left(l_{t}, x_{t}, \epsilon_{t}\right)$ of a female is given by a classical Mincer (1974) earnings equation with returns to experience, where full-time work $l_{t}=\frac{1}{2}$, see Equation (12). As a normalization $x_{t}$ is multiplied by two $\left(\tilde{x}_{t}=2 x_{t}\right)$ such that part-time work increases $\tilde{x}$ by 0.5 and full-time work by 1:

$$
\ln y_{t}=\eta_{0}+\eta_{1} \tilde{x}_{t}+\eta_{2} \tilde{x}_{t}^{2}+\epsilon_{t}
$$

\footnotetext{
${ }^{19}$ In the sample investigated here, $94 \%$ of all mothers work prior to the first birth.
} 
Figure 7: Income Profiles

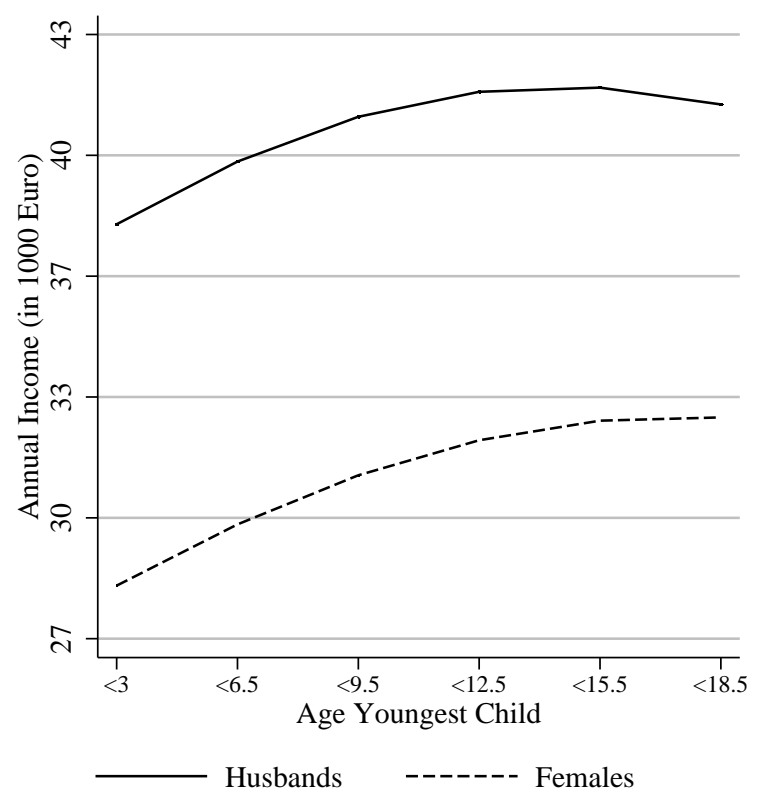

I assume that there is no part-time penalty, i.e. the gross part-time income is half of the gross full-time income for the same level of experience and the same income shock.

Appendix C.1 describes how the income processes are estimated. Given the specific structure of the model, standard estimates from the literature cannot be used. Moreover the feature of joint income taxation (see below) requires to to estimate a gross income process and apply the tax code afterwards, instead of estimating a net income directly, in order to capture the appropriate incentives for married females to work. The predicted income profiles are displayed in Figure 7. For the numerical solution of the model, the AR(1) process for the income shock (Equation (1)) is discretized into 20 states using the method proposed by Tauchen (1986).

\subsubsection{Taxes and Transfers}

The tax code implemented in the model incorporates the three key elements of the German tax system: mandatory social security contributions, progressive and joint taxation.

Employees, excluding civil servants, have to make mandatory contributions to the pension system, unemployment, long-term care and public health insurance which accrue proportionally to income up to a contribution limit. In the model I use the average contribution limits and rates for each type of insurance over the years 1983 to 2006. Similarly, the implemented tax code is based on the average income taxes over the sample period. The construction of the tax code is described in Appendix C.2 which also shows the final social security contributions and tax rates used in the model. In Germany legally married couples are taxed jointly, i.e. the tax code is applied to half of 
the sum of the spouses' incomes and the resulting tax burden is doubled. By the progressivity of the tax system the joint net income is always at least as large as the sum of the individually taxed incomes. Although my sample includes some cohabitating but not legally married couples, I apply joint taxation.

The transfers considered include the average child benefits over the the years 1983 through 2006 which are paid each period depending on the total number of children. The average benefit per child is slightly increasing in the number children, see Table C.4 in Appendix C.2. Based on the description in Ludsteck and Schoenberg (2007) non- and part-time working mothers receive in period one a maternity benefit of $2414.19 €$ which comprises the maternity benefits paid during the first six months after a child is born if the mother does not work.

\subsubsection{Child Care Fees}

The child care fees $f_{c c}\left[n, t, c c_{s, t}, c c_{n s, t}, y_{t}, y_{t}^{*}\right]$ are given by the per-child fees for subsidized and nonsubsidized child care multiplied by the number of children. The per-child fees for subsidized child care are the predicted values from a Tobit-regression with censoring at $0 €$ and at $447.72 €$, the lowest and highest observed monthly fee for subsidized child care with the following set of regressors: an intercept, a full-time dummy, a dummy for ages zero to two, number of further siblings enrolled in subsidized child care, and household income. ${ }^{20}$ The per-child fees for non-subsidized child care are the predicted values from an OLS-regression on a constant and a full-time dummy, the only two regressors that turned out to be statistically significant. The coefficients for both regressions and predicted fees are shown in Tables C.5 and C.6 in Appendix C.3.

\subsubsection{Subsidized Child Care Provision Rates}

The age- and type-dependent, i.e. part- and full-time, success probabilities in the lottery determining access to subsidized child care are taken from Figure 5 and are also shown in Table A.3 in Appendix A.3.

\subsubsection{School Hours}

I assume that children attend school part-time $\left(s_{t}=\frac{1}{4}\right)$ in periods three and four, i.e. for ages seven to 12.5 , and full-time $\left(s_{t}=\frac{1}{2}\right)$ in periods five and six, i.e. for ages 13 to 18.5. Schooling hours matter by limiting the maximum amount of time the mother can spend with her children, compare Equation (18).

\subsection{Data Targets}

The discount factor $\beta$ is set to $\left(\frac{1}{1.04}\right)^{3}$ as in Kydland and Prescott (1982). The remaining 12 preference parameters are calibrated by matching 12 moments that are grouped in three data

\footnotetext{
${ }^{20}$ The sibling discount and income dependence are part of the regulations for the subsidized child care fees. I define household income as the average monthly income of both spouses in the year the fee is observed deflated by the OECD equivalence scale given by Equation (3) to account for different household sizes.
} 
Table 4: Fertility Distribution

\begin{tabular}{lcccc} 
& \multicolumn{4}{c}{ Nr. of Children } \\
& $\mathbf{0}$ & $\mathbf{1}$ & $\mathbf{2}$ & $\mathbf{3}$ \\
\hline Fraction & 10.7 & 21.0 & 50.4 & 17.8 \\
& & & & \\
\hline $\begin{array}{l}\text { Note: Figures are based on the } 1140 \text { females } \\
\text { from the sample selected in Section } 2 \text { who have } \\
\text { completed their fertile period, assumed to end } \\
\text { at the age of forty. }\end{array}$
\end{tabular}

categories. In the following I assign each parameter to the group where the influence is felt the heaviest and outline in how far the data are informative about the respective parameter values. Since aggregate statistics are matched, as opposed to individual data, and all parameters jointly determine the model statistics, the following discussion is only suggestive and informal.

Fertility The preference parameters governing the utility of having children naturally have a strong influence on fertility outcomes. $\zeta$ matters most for the extensive margin, i.e. whether or not to have children, while $\delta_{2}$ and $\gamma_{2}$ are more important for the fertility distribution (in terms of number of children). I target the fraction of females without, with one and with two children. Table 4 shows the empirical fertility distribution for a maximum of three children per female which are adjusted for the fact that around $3.5 \%$ of all couples are unable to get children at all, see Robert Koch Institut and German Statistical Office (2004).

Labor Force Participation Since the focus of the analysis is on child care and thus the pre-school ages, I target the average (over all mothers) part- and full-time labor force participation rate when children are of ages zero to two and three to six and a half. In addition, both rates are targeted in the last period considered, i.e. when children are of ages 15.5 to 18.5. The six parameters governing the time allocation of the mother, i.e. leisure $\left(\delta_{1}\right.$ and $\left.\gamma_{1}\right)$ and time spend with the children $\left(\delta_{3}\right.$, $\gamma_{3}, \xi_{1}$ and $\xi_{2}$ ) have the tightest link to this data category. In particular, in period one neither $\xi_{1}$ nor $\xi_{2}$ have a direct impact on the utility of time spent with children since $\xi(1)=1 \forall \xi_{1}, \xi_{2}$. The labor force participation decision in period six is as well independent of $\xi_{1}$ but strongly influenced by $\xi_{2}$ which sets the utility of time spent with children in the last period. $\xi_{1}$ in turn determines how fast the utility of time spent with the children decreases and the functional form of Equation (8) implies the largest decrease to happen between period one and two. Accordingly the value of $\xi_{1}$ has a strong influence on the labor force participation rate in period two.

Furthermore, I target the difference in the part-time labor force participation rate between mothers with one and two children of age zero to two. This statistic is affected by $\gamma_{0}$ through the budget constraint where the effect of labor force participation is interacted with the number of children via the equivalence scale adjustment.

Child Care Enrollment I target the part- and full-time child care enrollment rate of children aged three to six and a half (again as averages over all mothers). The parameter $\phi_{1}$ gives the weight on the disutility of using non-paid child care and $\phi_{2}$ governs how costly it is to increase the usage of non-paid child care. 
Table 5: Targeted Data and Model moments

\begin{tabular}{lccc} 
Target & Data & Model & $\Delta_{\text {Data-Model }}$ \\
\hline Fertility & & & \\
Fraction of females & & & \\
$\quad$ without children & 10.7 & 10.1 & 0.6 \\
with one child & 21.0 & 20.0 & 1.0 \\
with two children & 50.4 & 51.2 & -0.8 \\
& & & \\
\hline
\end{tabular}

\section{Maternal Labor Force Participation Rate}

$\begin{array}{lrrr}\text { Part-time } & & & \\ \quad t=1 & 26.5 & 26.5 & 0.0 \\ t=2 & 53.2 & 54.3 & -1.1 \\ t=6 & 60.0 & 59.0 & 1.0 \\ \quad t=1 ; \Delta_{\{n=1\}-\{n=2\}} & 10.9 & 10.9 & 0.0 \\ \text { Full-time } & & & \\ \quad t=1 & 4.7 & 4.8 & -0.1 \\ t=2 & 8.4 & 8.2 & 0.2 \\ t=6 & 19.7 & 19.5 & 0.2\end{array}$

\section{Child Care Enrollment Rate}

Part-time

$\begin{array}{cccc}t=2 & 83.7 & 81.8 & 1.9 \\ \begin{array}{c}\text { Full-time } \\ t=2\end{array} & 11.6 & 12.9 & -1.3\end{array}$


Table 6: Preference Parameters

\section{Fertility}

Children $\quad \delta_{2}=1.12 \quad \gamma_{2}=1.39 \quad \zeta=0.53$

\section{Maternal Labor Force Participation}

\begin{tabular}{lllll} 
Consumption & $\gamma_{0}=1.98$ & & \\
Leisure & $\delta_{1}=0.23$ & $\gamma_{1}=2.33$ \\
Maternal time & $\delta_{3}=2.23$ & $\gamma_{3}=0.45$ & $\xi_{1}=0.03$ & $\xi_{2}=0.41$ \\
& & & & \\
\hline
\end{tabular}

\section{Child Care Enrollment}

$$
\text { Non-paid child care } \quad \phi_{1}=0.21 \quad \phi_{2}=2.45
$$

Since no closed form solution of the corresponding model moments is available, I simulate 100,000 individuals. The initial income shocks are drawn from the stationary distribution implied by the estimated parameters of Equation (1). Despite the discrete nature of all choices, small changes around the calibrated parameters induce small changes of the model statistics because of the large heterogeneity. This is also true for the fertility outcomes. Even the most likely initial combination of spousal income shocks occurs only with a probability of $1.7 \% .^{21}$

\subsection{Results}

Table 5 shows the data moments along with the simulated model moments for the calibrated model version. Table 6 lists the calibrated preference parameters sorted by the calibration targets with a reference to the corresponding parts in the utility function. Following the common practice when the number of calibrated parameters equals the number of matched data targets, I do not report standard errors for the calibrated preference parameters. Let me briefly comment on a few of the calibrated preference parameters. First, the curvature of consumption is in the range of usually cited values. Second, as already indicated before a value of $\zeta>0$ is required to make some women choose to not have children. Nevertheless, having children is always associated with a positive utility. Third, the utility of maternal time spent with the children decreases at a very modest

\footnotetext{
${ }^{21}$ I used for the calibration of the model parameters the asynchronous parallel pattern search algorithm described in Gray and Kolda (2006), and Kolda (2005). The corresponding software (APPSPACK) is freely available on the web (https://software.sandia.gov/appspack/version5.0/index.html) and was run in parallel mode on the Deutsche Bank/E-Finance Lab House of Finance Servercluster.
} 
speed as the children age $\left(\xi_{1}=0.03\right)$ and is for children aged 15.5 to 18.5 less than half of the utility for children aged zero to two $\left(\xi_{2}=0.41\right)$.

\section{Model Evaluation}

To judge the model's performance, I now turn to a set of non-targeted moments that are at the core of the analysis, namely child care enrollment for children aged zero to two and the joint maternal labor force participation and child care enrollment choices. $^{22}$

\subsection{Child Care Enrollment}

In the data the child care enrollment rate is substantially lower for children aged zero to two compared to children aged three to six and a half. In the model two mechanisms are at work that bring down enrollment in paid child care for the younger age group. First, the utility mothers receive from spending time with their children declines as the children get older. This in turn increases the incentive to use (more) paid and non-paid child care and to participate (more) in the labor market when the children are of ages three to six and a half compared to when the children are of ages zero to two. Second, the cost of using paid child care relative to non-paid child care are higher for children aged zero to two. While the usage of non-paid child care is assumed to be associated with the same utility costs for both pre-school age groups, the utility loss from the usage of paid child care through reduced consumption is very different. Mothers with children aged zero to two who want to use paid child care will mainly have to resort to non-subsidized child care because of the low availability of subsidized child care. In addition, paid child care is more expensive for children aged zero to two: in relative terms because the household income (conditional on the maternal labor force participation status) is on average lower; in absolute terms because subsidized child care fees are on average associated with an extra charge of up to $30 \%$ per month, compare Table C.6 in Appendix C.3.

The question is now how well these two mechanisms are jointly able to predict child care enrollment for children aged zero to two. E.g. it could be that the higher costs of paid child care do not matter at all if for working mothers without access to a subsidized slot, the costs of non-subsidized child care are still below the costs of using non-paid child care. As an implication, the predicted child care enrollment rates for children aged zero to two by the model would be much higher than in the data. The upper panel of Table 7 demonstrates that this is not the case. The two model mechanisms described above predict the full-time child care enrollment rate precisely $(0.5 \%$ vs. $0.6 \%)$ and the part-time child care enrollment rate falls only slightly short relative to the data (4.0\% vs. $5.6 \%$ ). The latter difference mainly stems from a too low usage of non-subsidized child care in the model compared to the data ( $14.8 \%$ vs. $40.4 \%)$. Nevertheless, both rates in the model still fall in the respective $95 \%$ confidence intervals and are qualitatively consistent with the low part-time child care enrollment rate for children aged zero to two in the data.

The model further predicts correctly that for children aged three to six and a half non-subsidized

\footnotetext{
${ }^{22}$ In Appendix D I discuss a set of non-targeted moments which were were only touched on in the presentation of stylized facts in Section 3.
} 
Table 7: Non-Targeted Moments: Child Care Enrollment Rates

\begin{tabular}{lcccc} 
& \multicolumn{2}{c}{ Ages 0 to 2 } & \multicolumn{2}{c}{ Ages 3 to 6.5 } \\
& Data & Model & Data & Model \\
\hline Part-time & 5.6 & 4.0 & TARGET \\
Full-time & {$[3.1 ; 8.2]$} & & \\
& 0.6 & 0.5 & TARGET \\
& {$[0.0 ; 1.3]$} & & \\
\hline & & & & \\
Fraction Enrolled in & 40.4 & 14.8 & 0.8 & 0.1 \\
Non-Subs. Care & {$[14.1 ; 66.7]$} & & {$[0.0 ; 2.0]$} & \\
& & & & \\
\hline
\end{tabular}

Note: $95 \%$ confidence intervals for the data moments are given in brackets.

Table 8: Non-Targeted Moments: Conditional Child Care Enrollment Rates

\begin{tabular}{lcccc} 
& \multicolumn{2}{c}{ Ages 0 to 2 } & \multicolumn{2}{c}{ Ages 3 to 6.5 } \\
& Data & Model & Data & Model \\
\hline \multirow{2}{*}{ At least part-time care } & & & & \\
Not Working & 2.9 & 2.7 & 93.2 & 92.1 \\
Working & {$[0.6 ; 5.1]$} & & {$[87.9 ; 98.7]$} & \\
& 13.7 & 11.6 & 96.7 & 96.4 \\
& {$[7.3 ; 20.5]$} & & {$[94.2 ; 99.1]$} & \\
& & & & \\
Full-time care & & & & \\
Full-time Working & 3.9 & 2.7 & 32.4 & 28.8 \\
& {$[0.0 ; 11.2]$} & & {$[16.7 ; 47.6]$} & \\
& & & & \\
\hline
\end{tabular}

Note: $95 \%$ confidence intervals for the data moments are given in brackets.

child care is irrelevant. This result is basically implied by the choice of calibration targets, i.e. by matching the part- and full-time child care enrollment rates for this age group at the prevailing provision rates of subsidized child care.

\subsection{Conditional Child Care Enrollment}

Table 8 shows that the child care enrollment rates conditional on the maternal labor force participation status predicted by the model are as well close to the data for both age groups. Very different outcomes for the conditional child care enrollment rates would have also been consistent 
with matching and explaining the (unconditional) child care enrollment and maternal labor force participation rates. E.g. all and not only $28.8 \%$ of the full-time working females with children aged three to six and a half $(8.2 \%$, see Figure 4$)$ could have been using full-time child care and the full-time child care enrollment rate (12.9\%, see Figure 4) could have been generated by a lower usage of full-time child care of non- and part-time working mothers.

The successful prediction of the conditional child care enrollment rates cannot be explained by a single mechanism in the model but rather reflects that the main trade-offs mothers face in real life are captured well by the model. Just to give one example: the assignment of subsidized child care slots is random and does not favor working women. This contributes to the relative low full-time child care enrollment rates conditional on working full-time. These outcomes are of course not independent from the costs of non-paid child care (also relative to non-subsidized child care) and the selection into full-time participation.

To sum up, with the focus of the paper being on the joint labor force participation and child care enrollment choices of mothers, the good predictions of the non-targeted child care moments provide confidence in the model's explanatory power.

\section{$7 \quad$ Policy Experiments}

In April 2008 the German Federal government, back then a coalition of christian (CDU/CSU) and social democrats (SPD), passed the Kinderförderungsgesetz [Kifög]. I evaluate the major parts of this law that concern the provision of subsidized child care for children aged zero to two.

\subsection{Setup of the Reforms}

REFORM 1: For all children younger than age three a subsidized child care slot shall be provided from October 2010 onwards if both parents are working. (§24 I 2 and §24a III Sozialgesetzbuch 8)

The bill on the Kifög was introduced with the following statement: "Many parents do not realize their desired fertility level, because of the incompatibility of family and working life ... Therefore it is necessary to improve the compatibility of family and working life. To achieve this, we need more high quality child care for children younger than age three." German Federal Parliament (2008) By this article, the coalition expected to achieve a child care enrollment rate of $35 \%$ of all children younger than age three, and thus compliance with the target of $33 \%$ set by the European Commission at its Barcelona meeting in 2002, and to close the gap to the "exemplary standards in Western and Northern European countries, for which a relationship between child care enrollment, maternal employment and fertility is observed", see Sharma and Steiner (2008). The reform is straightforward to implement in the context of the model by conditioning access to subsidized child care $\left(a_{1}\right)$ on the labor force participation status $\left(l_{1}\right)$ :

$$
a_{1} \geq l_{1}
$$

While full-time working females can always use subsidized part-time or full-time child care, I maintain the assumption that non-working females rely on the initially specified slot lottery to have 
access to subsidized child care. Part-time working females are in-between because they can always use subsidized part-time child care but subsidized full-time child care only if they are successful in the slot lottery.

REForm 2: From August 2013 onwards all children of age one and two are entitled to a subsidized child care slot. (§24 II Sozialgesetzbuch 8)

This passage can be seen in the tradition of providing subsidized child care as a means of affordable, high quality pre-school education also for children aged one to two. This view is confirmed in a dossier of the Federal Ministry of Family Affairs, Senior Citizens, Women and Youth (Sharma and Steiner (2008)) accompanying the Kifög in which among others the beneficial aspects of the enrollment in high-quality child care for infantile education are pointed out. Already in the 1990's an entitlement to a subsidized child care slot was introduced for children aged three to six and a half which referred to part-time slots only. ${ }^{23}$ I therefore assume that the "new" entitlement also refers to part-time subsidized child care. The actual law applies to all children of age one and two whereas the model period comprises ages zero to two, i.e. one year more. Given the variables definition employed in Section 2 and Appendix A.3, access to a subsidized part-time child care slot for only two years in the data still corresponds to access to a subsidized part-time child care slot for the whole model period. Hence, REForm 2 will be implemented such that all mothers of children aged zero to two have at least access to a subsidized part-time child care slot for their children independent of their labor force participation status. Non- and part-time working mothers might still draw from the lottery a subsidized full-time child care slot with the success probability from the Baseline setup.

Table 9 compares the Baseline setup with the previously described reforms. The parental fees for subsidized and non-subsidized child care are kept at the values of the Baseline setup.

I evaluate the impact of the reforms in three steps. I first compare the outcome from the Baseline setup with the two experiments holding the fertility choice fixed, i.e. I ask: how would the females behave if they had have made their fertility choice under the Baseline setup but then faced a setup as described by the respective reforms? This permits to disentangle the direct effect on maternal labor force participation and child care enrollment from the one induced through changes in the fertility choices. In the second step, I discuss the impact of each reform on the fertility choices. Afterwards I summarize the results for the female and maternal labor force participation rates and the child care enrollment rates taking the changes in the fertility outcomes into account and contrast them with case of holding fertility fixed.

As a word of caution, the experiments conducted here abstract from any problems in the actual implementation of the reforms. No one expects the promised subsidized child care slots to be fully available at the date of the implementation of the law, and in fact for the 2010 reform they have not been. It will rather take a few (more) years until the predictions of the paper maybe contrasted with the empirical data.

\footnotetext{
${ }^{23}$ Note that in the Baseline setup the total provision rate of subsidized child care for children aged three to six and a half is only $95.6 \%$ because of the lower provision rates in the first half of the observation period (up to the mid 1990's). Increasing the provision rate of part-time subsidized child care from $71.5 \%$ to $75.9 \%$ for children aged three to six and a half in the calibrated model, i.e. for each child at least a part-time subsidized child care slot is available, has no qualitative impact on the results.
} 
Table 9: Policy Regimes

\begin{tabular}{ccc} 
Access Probability (in \%) to ... Subsidized Child Care & Sub \\
No & Part-time & Full-time \\
\hline
\end{tabular}

\section{Ages 0 to 2}

$\begin{array}{lrlrlrl}\text { Baseline } & 94.0 & \forall l & 4.3 & \forall l & 1.7 \quad \forall l \\ & 94.0 & \text { if } l=0 & 4.3 \text { if } l=0 & 1.7 \text { if } l \leq \frac{1}{4} \\ \text { REFORM 1 } & 0.0 & \text { else } & 100.0 \text { else } & 100.0 \text { else } \\ & & & & & 1.7 \text { if } l \leq \frac{1}{4} \\ \text { REFORM 2 } & 0.0 & \forall l & 100.0 \quad \forall l & 100.0 \quad \text { else }\end{array}$

Note: $l=0 / \frac{1}{4} / \frac{1}{2}$ corresponds to non-/part-/full-time working.

\subsection{Labor Force Participation and Child Care Enrollment with Fixed Fertility}

Table 10 restates the maternal labor force participation and child care enrollment rates from the Baseline setup and the resulting change in percentage points under each reform. The fertility choices are held constant at their values from the Baseline setup.

Ages 0 to 2 Under Reform 1, all part-time (full-time) working mothers with children aged zero to two have access to a part-time (full-time) subsidized child care slot. Part-time working mothers may still gain access to a full-time slot through the initial lottery whereas non-working women entirely rely on the initial lottery. This policy increases the part- and full-time maternal labor force participation rates by 3.2 and 1.7 percentage points, respectively. Thus in total 4.9 percentage points or $15.7 \%$ more mothers are working. For these mothers the lack of subsidized child care constituted a barrier to work. Mothers with children aged zero to two still work substantially less than mothers with children aged three to six and a half. Under REFORM 1 this difference cannot be attributed any longer to the lack of subsidized child care but rather stems from the two following sources: first, the subsidized child care fees for children in the younger age group are on average associated with an extra charge of up to $30 \%$ per month, compare Table C.6 in Appendix C.3. Second, the utility from spending a given unit of time with children aged three to six and a half is lower than for children aged zero to two (by 23\%).

Although the settings are not fully comparable, it is worthwhile to mention that the increase in maternal labor force participation is very similar to difference-in-differences estimates from a drastic increase of subsidized child care in the late 1990's in the Canadian province of Quebec. Baker, Gruber, and Milligan (2008) estimate for two-parent families an increase of the maternal labor force participation rate of 7.7 percentage points or $14.5 \%$ and Lefebvre and Merrigan (2008) estimate for all mothers an increase of up to 8.1 percentage points or 13\%. Further supportive evidence giving credibility to the model predictions regards the price elasticity of maternal labor force participation with respect to the costs of paid child care. Blau and Currie (2006) summarize 
Table 10: Fixed Fertility - Maternal Labor Force Participation and Child Care Enrollment

\begin{tabular}{|c|c|}
\hline ipa & \\
\hline Full-time & Part-time \\
\hline
\end{tabular}

Ages 0 to 2

\begin{tabular}{lrrrr} 
Baseline & 26.5 & 4.8 & 4.0 & 0.5 \\
REFORM 1 & +3.2 & +1.7 & +27.3 & +6.3 \\
REFORM 2 & +3.2 & +1.7 & +53.7 & +6.3 \\
& & & & \\
\hline
\end{tabular}

Ages 3 to 18.5 (Avg.)

$\begin{array}{lrrrr}\text { Baseline } & 60.0 & 10.8 & - & - \\ \text { REFORM 1 } & 0.0 & 0.0 & - & - \\ \text { REFORM 2 } & 0.0 & 0.0 & - & -\end{array}$

Note: The entries for the Baseline scenario refer to the maternal labor force participation and child care enrollment rates prior to REFORM 1 and 2. The entries for REFORM 1 and 2 refer to the percentage point changes of the respective maternal labor force participation and child care enrollment rates relative to the Baseline scenario.

price elasticities from 20 studies for the US. The smallest elasticities in absolute value are found by Ribar (1995), Blau and Hagy (1998), and Tekin (2007), the only three studies that allow for non-paid, non-maternal child care. The elasticity implied by REFORM 1 is -0.2 and coincides with the upper bound (in absolute value) of the range of estimates from these three studies (-0.09 to $-0.2) .{ }^{24}$

The increase in the child care enrollment rates induced by REFORM 1 is with 27.3 and 6.3 percentage points much larger than for maternal labor force participation because mothers that worked in the Baseline setup without using paid child care now substitute non-paid with subsidized child care. This documents a large excess demand for subsidized child care among working mothers. The difference between REFORM 1 and REFORM 2 for children aged zero to two is that non-working females also have access to a subsidized part-time child care slot. Under this setup an additional 26.4 (53.7-27.3) percentage points of the mothers are starting to use subsidized part-time child care. The fact that none of the other variables changes implies that under REFORM 1 no mother is only working to be able to use subsidized child care. With the exception of the access to subsidized full-time child care, REFORM 2 introduces a setup for children aged zero to two comparable to the Baseline setup for children aged three to six. Only $63 \%$ of the mothers with children in this age group are working in the Baseline setup but $95 \%$ are using subsidized child care. The implied gap of 32 percentage points is very similar to the gap of 29 percentage points for children aged zero

\footnotetext{
${ }^{24}$ I compute this elasticity only for the model with fixed fertility as the reference studies employ models with exogenous, and thus fixed, fertility.
} 
Figure 8: Policy Effects with Fixed Fertility by Potential Income
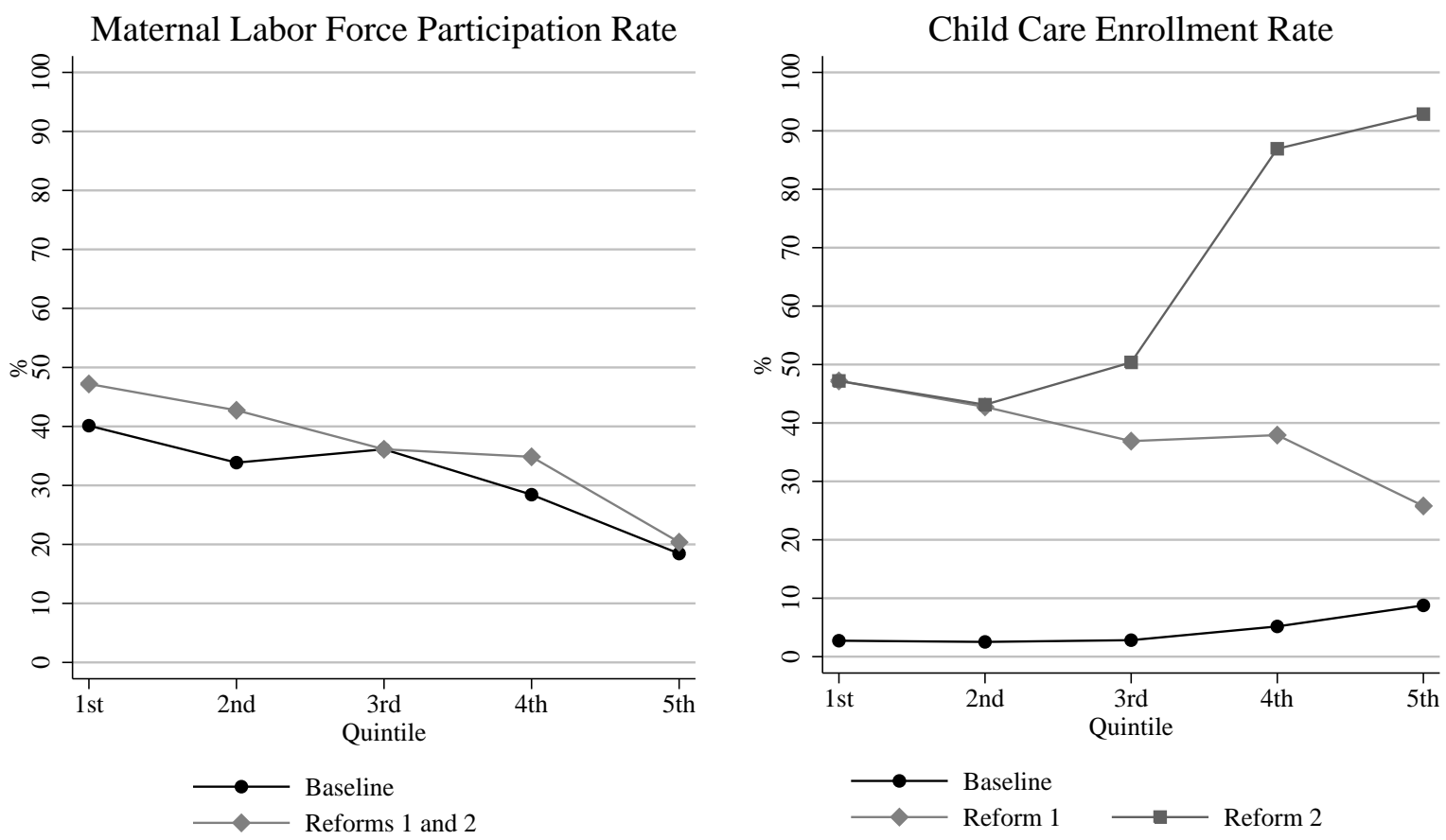

to two under REFORM 2, where $36 \%$ of the mothers are working but $65 \%$ are using child care. Put differently, with the same access to subsidized part-time child care for both age groups, the fraction of females not working but using paid child care is nearly the same for both age groups under REFORM 2.

As mentioned before, one goal of REFORM 2 is to provide affordable, high quality pre-school education also for children in this age group. This presumes that child care has a beneficial aspect on the children's human capital which is however not captured by the child quality measure employed in this paper and also out of the scope of the analysis. Nevertheless, from the perspective of policy makers the higher enrollment rates can thus be judged as a success of REFORM 2. Therefore it is of further interest which mothers and thus which children are most affected by REFORMS 1 and 2 as it is often argued that high quality child care is particular beneficial for children from low income families. While this latter hypothesis cannot be addressed, the model makes predictions on the former question.

Figure 8 compares the maternal labor force participation rates (left panel) and child care enrollment rates (right panel) under the Baseline scenario and REFORMS 1 and 2 by potential income quintiles. These are constructed with the period one, gross joint income of all couples with children assuming the female would be working full-time. This measure has two advantages over the actual gross joint income. First, otherwise the quintiles of the Baseline scenario would not be comparable to those of REFORMS 1 and 2 because of the change in the labor force participation choices. Second, one and two earner couples with the same actual joint gross (or even net) income might have very different 
incentives to use child child care because of the different female labor force participation statuses.

Under REFORM 1 the largest (percentage point) increase of the maternal labor force participation rate occurs for mothers from the first and second quintile. As all working mothers in this scenario use subsidized child care, the increase and the level of the child care enrollment rate in the two lowest potential income quintiles is as well the highest. This is in stark contrast to REFORM 2 where only households with a non-working woman from the upper quintiles, mainly the fourth and the fifth, afford the additionally available subsidized child care. Hence, while potential income poor families benefit disproportionately from REFORM 1, only potential income rich households benefit from REFORM 2. This latter result could be reversed or at least mitigated by lowering the fees further for low income households.

Ages 3 to 18.5 The higher accumulated experience when the children are of ages zero to two does neither affect maternal labor force participation nor child care enrollment later in life relative to the Baseline setup. This is because all females affected by the reforms would anyway participate in the labor market once their children turn three.

To sum up, for the same fertility choices as in the Baseline setup, REFORM 1 demonstrates that the lack of subsidized child care for children aged zero to two constitutes a barrier to start working or to work more. The total maternal labor force participation rate goes up by $15 \%$ or 4.9 percentage points, comparable to the Quebec experience, and the full-time maternal labor force participation rate even by $35 \%$ or 1.7 percentage points. The implied elasticity of maternal labor force participation with respect to the child care costs is of a similar magnitude than those obtained from other studies allowing for non-paid child care. These changes in the maternal labor force participation rates do however not lead to an increased labor supply later in life. Furthermore, according to REFORM 2 there is also a substantial excess demand for subsidized child care among non-working mothers of children aged zero to two. Finally, while potential income poor families benefit disproportionately from REFORM 1, only potential income rich households benefit from REFORM 2.

\subsection{Fertility}

In the previous subsection fertility choices were fixed to those from the Baseline specification. Increasing the availability of subsidized child care might however affect the fertility choices as well. Table 11 compares the fraction of females with zero to three children from the Baseline setup to those when fertility is allowed to respond optimally to the new settings under REFORMS 1 and 2.

Under REFORM 1 the fraction of females without children decreases by 2.9 percentage points, i.e. by nearly $30 \%$. For the fraction of females with two children only the net change is 0.0 . In fact, 0.8 percentage points of the females with one child switch to having two children and 0.8 percentages of the females with two children switch to having three children. The total increase in the fertility rate amounts to 0.05 children per female. In analogy to the previously cited introductory statement of the Kifög German Federal Parliament (2008), REForm 1 allows more parents to have their first child or more children by improving the compatibility between family and working life through the provision of subsidized child care. These small effects are consistent with the empirical evidence provided in Hank and Kreyenfeld (2003) who do not find a significant impact of the availability of subsidized child care on first and second birth risks in Germany using the variation in the provision 
Table 11: Policy Effect on Fertility

\begin{tabular}{lccccc} 
& \multicolumn{4}{c}{ Fraction with n children } & Fertility \\
& $\mathbf{0}$ & $\mathbf{1}$ & $\mathbf{2}$ & $\mathbf{3}$ & Rate \\
\hline \multirow{2}{*}{ Baseline } & 10.1 & 20.0 & 51.2 & 18.7 & 1.78 \\
REFORM 1 & -2.9 & +2.1 & 0.0 & +0.8 & +0.05 \\
REFORM 2 & -2.9 & +2.1 & 0.0 & +0.8 & +0.05 \\
& & & & & \\
\hline
\end{tabular}

Note: The entries for the Baseline scenario refer to the fertility distribution and fertility rate prior to REFORM 1 and 2. The entries for REFORM 1 and 2 refer to the change of the fertility distribution and the fertility rate, respectively, relative to the Baseline scenario.

of subsidized child care across German counties (Kreise).

Under REFORM 2 additionally non-working mothers of children aged zero to two are granted access to subsidized child care. There is no further reaction in the fertility distribution or fertility rate relative to REFORM 1. Put differently, only those females who are constrained in their labor force participation choice through the lack of subsidized child care are also constrained in their fertility choice.

\subsection{Labor Force Participation and Child Care Enrollment with Flexible Fertility}

Table 12 compares the maternal labor force participation and child care enrollment rates under REFORMS 1 and 2 with the Baseline scenario for the flexible (endogenous) fertility choice. The parttime (full-time) labor force participation rate of mothers with children aged zero to two increases by 5.0 (2.4) percentage points if fertility is flexible but only by 3.2 (1.7) percentage points if fertility is held fixed, see also Table 10. These differences are reflected one to one (in percentage points) in higher part- and full-time child care enrollment rates. The larger maternal labor force participation with flexible fertility also transpires (in contrast to fixed fertility) to the later ages and stems from two sources. First, to support the larger family size more mothers are working (more). Second, the sample of mothers is increased by the previously childless females which have a higher tendency to participate in the labor market. This latter point however also shows that it is in fact misleading to compare maternal labor force participation rates. Ultimately, most relevant for the economy are the changes in the female labor force participation rate which are compared in Table 13 for the fixed and flexible fertility scenario.

Both for ages zero to two, for childless females this refers to period $t=1$ in the life-cycle, and on average over the entire life-cycle, accounting for the adjustment in fertility results in higher parttime female (not maternal) labor force participation rates but lower full-time female labor force participation rates. The key reason is that the previously childless females used to work full-time when not having children but switch (at least partly) to part-time participation in order to spend time with their newly born children. Following the previously made assumption that part-time work is half of full-time work, one can calculate the change in aggregate female labor input relative 
Table 12: Flexible Fertility - Maternal Labor Force Participation and Child Care Enrollment

\section{Participation Enrollment \\ Part-time Full-time Part-time Full-time}

Ages 0 to 2

$\begin{array}{lrrrr}\text { Baseline } & 26.5 & 4.8 & 4.0 & 0.5 \\ \text { REFORM 1 } & +5.0 & +2.4 & +29.1 & +7.0 \\ \text { REFORM 2 } & +5.0 & +2.4 & +54.6 & +7.0\end{array}$

\begin{tabular}{|c|c|c|c|c|}
\hline \multicolumn{5}{|c|}{ Ages 3 to 18.5 (Avg.) } \\
\hline Baseline & 60.0 & 10.8 & - & - \\
\hline REFORM 1 & +0.1 & +0.7 & - & - \\
\hline REFORM 2 & +0.1 & +0.7 & - & - \\
\hline
\end{tabular}

Table 13: Fixed vs. Flexible Fertility - Female Labor Force Participation

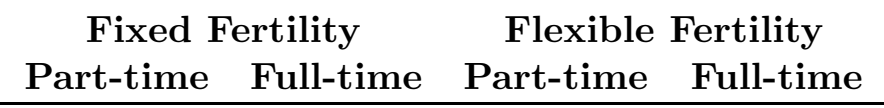

Ages 0 to 2

Baseline

23.8

14.4

23.8

14.4

REFORMS 1 and $2+2.9$

$+1.5$

$+5.4$

$-0.5$

\section{Life-cycle Averages}

$\begin{array}{lrrrr}\text { Baseline } & 49.3 & 18.5 & 49.3 & 18.5 \\ \text { REFORMS 1 and 2 } & +0.5 & +0.2 & +2.3 & -1.5\end{array}$

Note: The entries for the Baseline scenario refer to the female labor force participation rates prior to REFORM 1 and 2. The entries for REFORM 1 and 2 refer to the percentage point changes of the respective female labor force participation rates relative to the Baseline scenario. For childless females Ages 0 to 2 refer to period $t=1$ in the life-cycle. 
Table 14: Fixed vs. Flexible Fertility - Government Budget

Fixed Fertility Flexible Fertility

REFORM 1 REFORM 2 REFORM 1 REFORM 2

$\begin{array}{lcccc}\text { Tax Revenue (TR) } & +0.8 & +0.8 & +0.5 & +0.5 \\ \text { TR - Child Care Subs. (CCS) } & -1.1 & -2.8 & -1.6 & -3.4 \\ \text { Social Security Contributions }^{\dagger} \text { (SSC) } & +0.5 & +0.5 & +0.2 & +0.2 \\ \text { TR - CCS + SSC } & -0.1 & -0.8 & -0.5 & -1.2\end{array}$

Note: Each entry refers to the percentage point change of the discounted sum over all periods for the respective categorie (e.g. Tax Revenue) relative to the Baseline scenario. The same discount factor as in the optimization problem is used, i.e. $\left(\frac{1}{1.04}\right)^{3}{ }^{\dagger}$ Employee and Employer Contributions

to the Baseline scenario for the case of fixed and flexible fertility. For children aged zero to two, i.e. the first period in the life-cycle, the female labor force participation rate changes by 2.95 percentage points $\left(2.9 \times \frac{1}{2}+1.5\right)$ if fertility is hold fixed at the pre-reform choices and by 2.2 percentage points $\left(5.4 \times \frac{1}{2}-0.5\right)$ if fertility responses optimally to the new environment. When averaging over the entire life-cycle the changes are +0.45 percentage points for the former case, and -0.35 percentage points for the latter. This shows a strong overestimation of the implied labor supply responses for all females if one does not allow for the adjustment in the fertility choice and points to the importance of endogenizing fertility even though the change in the fertility rate is relatively small.

A final interesting question concerns the government budget effects of the two reforms. Obviously, given the pure life-cycle setup I am not able to account for any general equilibrium effects, e.g. the effect of the increased labor supply on equilibrium wages or of a higher fertility rate on the social security system in the future. Nevertheless, it is relatively simple to calculate the net effects at the given tax rates and costs of subsidizing a particular child care slot. While there is no information about the fixed costs of creating a subsidized child care slot (e.g. building a new or extending an existing facility), Kolvenbach, Haustein, Krieger, Seewald, and Weber (2004) report that the subsidies cover on average around $75 \%$ of the operating expenses per subsidized child care slot or alternatively, on average the parental fees correspond to $25 \%$ of the operating expenses. I therefore abstract from any fixed costs and assume that the costs for each type of subsidized child care slot (distinguished by age group and part- or full-time) is four times the corresponding average reported fee in the GSOEP. The government has to bear theses costs for all used child care slots which are however reduced by the parental fees.

Table 14 lists the discounted (over the six periods) effects on the government budget over the entire life-cycle. Since the labor supply and fertility responses are the same under REFORMS 1 and 2, the tax revenue (TR) and social security contributions (SSC) are as well the same. Moreover, given the lower aggregate female labor supply they are smaller if fertility is flexible (endogenous). Abstracting from the employee and employer social security contributions, the fixed fertility scenario is associated with a 1.1 percentage points lower government budget for REFORM 1 whereas the flexible fertility scenario is associated with a 1.6 percentage points lower government budget, both measured relative to the Baseline scenario. Put differently the costs of REFORM 1 are higher by 
$1 / 3$ if the fertility response is considered as well. For REFORM 2 the costs are about $1 / 5$ larger. If the additional employee and employer social security contributions are added to an extended government budget, the latter only decrease by -0.1 percentage points for REFORM 1 in the case of fixed fertility but still amounts to -0.5 percentage points if fertility is flexible, i.e. 5 times larger. For REFORM 2 the difference is only around $1 / 2$. While these numbers certainly have to be taken with caution, e.g. any fixed costs of offering more subsidized child care slots and any general equilibrium effects are ignored, these results show that it is important to endogenize fertility even if the effect on the fertility rate alone is small. The key reason is that the previously childless females used to work full-time when not having children but switch (at least partly) to part-time participation in order to spend time with their newly born children.

\subsection{Summary}

REFORM 1 achieves both goals it was set out to. Through the provision of subsidized child care conditional on the maternal labor force participation status not only barriers for the labor force participation of mothers with children aged zero to two but also for the fertility choices are removed. The fertility rate increases by 0.05 children per female. Despite the small effect on the fertility rate, it is important to endogenize fertility as in this case the aggregate female labor force participation rate decreases (opposed to the case of fixed/exogenous fertility). Furthermore, the German government expected to achieve a child care enrollment for children aged zero to two of $35 \%$. The resulting child care enrollment rate is with $40.6 \%$ not that much above the expected level. Given the higher maternal labor force participation rates, households with a low potential income benefit disproportionately from REFORM 1.

Under REFORM 2 which is supposed to become effective three years after REFORM 1 additional 25.5 percentage points of the children will be enrolled in child care. This was the intention of the reform. There is however no additional effect on the fertility rate as only females constrained in their labor force participation choice are constrained in their fertility choice through the lack of subsidized child care. In contrast to REFORM 1, only the potential income rich households with non-working mothers take advantage of the additional subsidized child care slots provided by REFORM 2.

\section{Conclusion}

At its Barcelona meeting in March 2002, the European Council recommended its member states to improve the provision of child care and even set explicit target levels. The intention of the initiative was to remove barriers for female labor force participation and possibly foster fertility. This paper asks within the context of a life-cycle model how important the provision of child care is quantitatively for female labor force participation and fertility.

In line with the facts of a cross-section of OECD countries, I document for a sample of married females in West Germany that the maternal labor force participation rate is substantially larger than the child care enrollment rate for children aged zero to two whereas the opposite is the case for children aged three to six and a half. Put differently, the correlation between the maternal labor 
force participation and child care enrollment rates is weak whereas the correlation of both variables, particularly the child care enrollment rate, with the childrens' age is large. Historical experience and empirical evidence for Germany suggest that the supply of subsidized child care is fixed in the short run despite an excess demand for it, in particular for children aged zero to two. The key question asked in this paper is in how far this fixed supply of subsidized child care at the given prices for rationed subsidized and non-rationed non-subsidized child care affects the maternal labor force participation, child care enrollment and fertility choices. To address this issue I endogenize these choices within a quantitative, dynamic life-cycle model and distinguish between maternal care, paid child care provided in public (subsidized) and market (non-subsidized) arrangements as well as non-paid child care (e.g. by grandparents). The option of non-paid, non-maternal child care is crucial to explain the observed age-dependent relationships between maternal labor force participation and child care enrollment and to avoid biased preference parameter estimates, see Blau (2003). This point is neglected by the majority of studies analyzing child care and female labor force participation, in particular by all that feature an endogenous fertility choice.

I use a calibrated version of the model to evaluate two policy reforms passed by the German government in 2008. In particular, the first reform aims at implementing the targets for child care provision set by the European Council by providing working mothers with subsidized child care slots. The results of the two experiments can be summarized as follows. Increasing the provision of subsidized child care increases the maternal force participation rate while children are of ages zero to two. The maternal labor supply responses and elasticity with respect to the cost of child care are consistent with other empirical estimates. However, only females that are constrained in their labor force participation choice by the lack of subsidized child care are also constrained in their fertility choice. Although the effect on fertility is small, I show that with regard to the overall effect on female labor supply and the costs of the reforms it is important to take the fertility adjustment in response to the reforms into account. Otherwise the labor supply effects are substantially overestimated whereas the costs are underestimated. Finally, it has to be kept in mind that the results only apply to a selected sample of females, namely those in stable long-term relationships, and not necessarily to the whole population of females.

Since the low maternal labor force participation, child care enrollment and fertility rates in Germany are representative for Continental Europe, the derived policy implications should be of interest for other Continental European countries. The results of the evaluated reforms suggest that increasing the provision of child care may not be sufficient for Continental Europe to catch up to with the high maternal labor force participation and fertility rates in Western and Northern Europe. Differences along other dimensions, in particular aspects of taxation, might matter much more, see e.g. Jaumotte (2003) or Manuelli and Seshadri (2009).

\section{References}

Apps, P., And R. Rees (2005): "Gender, Time Use and Public Policy over the Life Cycle," Oxford Review of Economic Policy, 21(3), 439-461.

Attanasio, O., H. Low, and V. Sanchez-Marcos (2008): "Explaining Changes in Female Labor Supply in a Life-Cycle Model," American Economic Review, 98(4), 1517-1542. 
Baker, M., J. Gruber, and K. Milligan (2008): "Universal Child Care, Maternal Labor Supply and Family Well-Being," Journal of Political Economy, 116(4), 709-745.

Bernal, R. (2008): “The Effect of Maternal Employment and Child Care on Children's Cognitive Development," International Economic Review, 49(4), 1173-1209.

Bick, A. (2011): "Maternal Labor Force Participation in West and East Germany," mimeo, Goethe University, Frankfurt.

Blau, D. (2003): "Child Care Subsidy Programs," in Means-Tested Transfer Programs in the United States, ed. by R. A. Moffitt, chap. 9, pp. 443 - 516. NBER.

Blau, D., And J. Currie (2006): "Preschool, Day Care, and After School Care? Whos Minding the Kids," in Handbook on the Economics of Education, ed. by E. Hanushek, and F. Welch, vol. 2, chap. 20. North Holland Press.

Blau, D. M., And A. P. Hagy (1998): "The Demand for Quality in Child Care," Journal of Political Economy, 106(1), 104-146.

Blau, D. M., and P. K. Robins (1989): "Fertility, Employment, and Child-Care Costs," Demography, 26(2), pp. 287-299.

(1991): "Child Care Demand and Labor Supply of Young Mothers over Time," Demography, 28(3), pp. 333-351.

Del Boca, D. (2002): "The effect of child care and part time opportunities on participatn and fertility decisions in Italy," Journal of Population Economics, 15, 549-573.

Del Boca, D., and R. M. Sauer (2009): "Life cycle empolyment and fertility across institutional environments," European Economic Review, 53, 274-292.

DomeiJ, D., And P. Klein (2010): "Should day care be subsidized?," Working paper, Stockholm School of Economics.

Erosa, A., L. Fuster, and D. Restuccia (2010): "A General Equilibrium Analysis of Parental Leave Policies," Review of Economic Dynamics, 13(4), 742 - 758.

European Council (2002): "Barcelona European Council," Presidency Conclusions SN 100/1/02 REV 1.

Fehr, H., And D. Ujhelyiova (2010): "Fertility, Female Labor Supply, and Family Policy," SSRN eLibrary.

Francesconi, M. (2002): "A Joint Dynamic Model of Fertility and Work of Married Women," Journal of Labor Economics, 20(2), 336-380.

German Federal Parliament (2008): "Entwurf eines Gesetzes zur Förderung von Kindern unter drei Jahre in Tageseinrichtungen und in der Kindertagespflege (Kinderförderungsgesetz Kifög)," Drucksache 16/10173. 
Gray, G. A., And T. G. Kolda (2006): "Algorithm 856: APPSPACK 4.0: Asynchronous Parallel Pattern Search for Derivative-Free Optimization," ACM Transactions on Mathematical Software, $32(3), 485-507$.

Greenwood, J., N. Guner, and J. A. Knowles (2003): "More on Marriage, Fertility and the Distribution of Income," International Economic Review, 44(3), 827-826.

Guner, N., R. Kaygusuz, and G. Ventura (2010): "Taxation and Household Labor Supply," Working paper, Universitat Autònoma de Barcelona.

Guner, N., And J. Knowles (2009): "Why is the rate of single-parenthood lower in Canada than in the U.S.? A dynamic equilibrium analysis of welfare policies," Canadian Journal of Economics/Revue canadienne d'conomique, 42(1), 56-89.

HaAn, P., And K. Wrohlich (2011): "Can Child Care Policy Encourage Employment and Fertility? Evidence from a Structural Model," Labour Economics, pp. 498-512.

Hank, K., And M. Kreyenfeld (2003): "A Multilevel Analysis of Child Care and Women's Fertility Decisions in Western Germany," Journal of Marriage and Family, 65, 584-596.

Heckman, J. J. (1974): "Effects of Child-Care Programs on Women's Work Effort," The Journal of Political Economy, 82(2), pp. S136-S163.

Hotz, V. J., And R. A. Miller (1988): “An Empirical Analysis of Life Cycle Fertility and Female Labor Supply," Econometrica, 56(1), 91-118.

Jaumotte, F. (2003): "Female Labour Force Participation - Past Trends and Main Determinants in OECD Countries," Working Paper 376, OECD Economics Department.

Jones, L. E., A. Schoonbroodt, and M. Tertilt (2001): Demography and the Economychap. Fertility Theories: Can They Explain the Negative Fertility-Income Relationship? NBER.

KoldA, T. G. (2005): "Revisiting asynchronous parallel pattern search for nonlinear optimization," SIAM Journal on Optimization, 16(2), 563-586.

Kolvenbach, F.-J., T. Haustein, S. Krieger, H. Seewald, and T. Weber (2004): "Kindertagesbetreuung in Deutschland," Report, German Statistical Office.

Kravdal, O. (1996): "How the Local Supply of Day-Care Centers Influences Fertility in Norway: A Parity-Specific Approach.," Population Research and Policy Review, 15(3), 201 - 218.

Kreyenfeld, M., K. Spiess, and G. G. Wagner (2002): "Kinderbetreuungspolitik in Deutschland," Zeitschrift für Erziehungswissenschaft, 5(2), 201-221.

Kydland, F. E., and E. C. Prescott (1982): "Time to Build and Aggregate Fluctuations," Econometrica, 50, 1345-1370.

Lefebvre, P., and P. Merrigan (2008): "Child-Care Pliy and the Labor Supply of Mothers with Young Children: A Natural Experiment from Canada," Journal of Labor Economics, 26(3), 519-548. 
Lehrer, E. L., and S. Kawasaki (1985): "Child Care Arrangements and Fertility: An Analysis of Two-Earner Households," Demography, 22(4), pp. 499-513.

Ludsteck, J., And U. Schoenberg (2007): "Maternity Leave Legislation, Female Labor Supply, and the Family Wage Gap," Working paper, IZA.

Manuelli, R. E., And A. Seshadri (2009): "Explaining International Fertility Differences," The Quarterly Journal of Economics, 124(2), 771-807.

Mason, K. O., and K. Kuhlthau (1992): "The Perceived Impact of Child Care Costs on Women's Labor Supply and Fertility," Demography, 29(4), pp. 523-543.

Mincer, J. (1974): Schooling, Experience and Earnings. New York: National Bureau of Economic Research.

OECD (2007): Babies and Bosses - Reconciling Work and Family Life: A Synthesis of Findings for OECD Countries.

Ribar, D. C. (1995): "A Structural Model of Child Care and the Labor Supply of Married Women," Journal of Labor Economics, 13(3), pp. 558-597.

Robert Koch Institut, and German Statistical Office (2004): "Ungewollte Kinderlosigkeit," Gesundheitsberichterstattung des Bundes, 20.

Sharma, M. R., and M. Steiner (2008): "Ausbau der Kinderbetreuung - Kosten, Nutzen, Finanzierung," Dossier, Federal Ministry of Family Affairs, Senior Citizens, Women and Youth.

Tauchen, G. (1986): "Finite State Markov-Chain Approximations to Univariate and Vector Autoregressions," Economic Letters, 20, 177-181.

TEkin, E. (2007): "Childcare Subsidies, Wages, and Employment of Single Mothers," J. Human Resources, XLII(2), 453-487.

Wagner, G. G., J. R. Frick, and J. Schupp (2007): "The German Socio-Economic Panel Study (SOEP) - Scope, Evolution and Enhancements," Schmollers Jahrbuch, 127(1), 139-169.

Wrohlich, K. (2006): "Labor Supply and Child Care Choices in a Rationed Child Care Market," Working paper, IZA.

(2008): "The excess demand for subsidized child care in Germany," Applied Economics, $40,1217-1228$. 


\section{A Data Appendix}

\section{A.1 Sample Selection}

Table A.1: Sample Selection Criteria

\begin{tabular}{lcc} 
& \multicolumn{2}{c}{ Frequency } \\
Criterion & Absolute & Relative \\
\hline West German ${ }^{\dagger}$, born 1955-1975 & 4921 & $100.0 \%$ \\
No move to East German territory & 4881 & $99.2 \%$ \\
$\quad$ Mothers & 2868 & $58.8 \%$ \\
Childless & 2013 & $41.2 \%$ \\
& & \\
\hline & & \\
Mothers & 2868 & $100.0 \%$ \\
Births only in relationships & 2276 & $79.4 \%$ \\
Births only in one relationship & 2238 & $78.0 \%$ \\
Relationship intact at last interview & 1938 & $67.6 \%$ \\
& & \\
\hline & & \\
Childless & 2013 & $100.0 \%$ \\
At least age forty at last interview & 424 & $21.1 \%$ \\
and in a relationship at age forty & & \\
Relationship intact at last interview & 177 & $8.8 \%$
\end{tabular}

Source: GSOEP 1984-2007.

$\dagger$ Females are assigned to West Germany by their location in 1989 or, if this information is not available, by the sample region at their first interview.

The focus of this paper is on labor force participation choices by mothers rather than childless females. In addition, I do not investigate the timing and spacing of births but only completed fertility choices. Hence, childless females are only used for the fertility analysis and therefore only included if they are at their last interview at least of age forty, the assumed age of the end of a woman's fertile period, and if their current relationship started prior to age forty such that they at least theoretically could have had given birth to a child during that marital spell. 


\section{A.2 GSOEP Child Care Questions}

Child Care Enrollment Imputation Information on the child care enrollment status for each child is only available at the interview date, i.e. usually once a year, and is therefore imputed for the other months of the year based on the following reasoning: Since school starts at the same time for all children (at least within one state), the oldest cohort in a daycare center leaves the daycare center together at the same time of the year, i.e. usually at the end of the first half of the year. Therefore the majority of entries into daycare centers occurs at the beginning of the second half of the year. Hence, the child care enrollment status in the first half (January to June) of a year is a good predictor for the status in the second half (July to December) of the previous year. Similarly, the child care enrollment status in the second half of a year is a good predictor for the child care enrollment status in first half of the next year. If the interview month is in the first half of the year, which is the case for more than $90 \%$ of the interviews, I use this child care enrollment status also for the second half of the previous year if no interview has been conducted in the second half of the previous year. Analogously, if the interview month is in the second half of the year I use this child care enrollment status also for the first half of the next year if no interview is conducted in the first half of the next year. Although this reasoning applies more to child care provided in daycare centers, I use the same imputation rule for child care provided by nannies.

Aggregate Statistics Prior to 1995, the GSOEP questionnaire only covered enrollment in child care whereas from 1995 onwards a distinction between daycare centers and nannies was made. In particular, between 1995 and 1999 the distinction between daycare centers and nannies was exclusive and from 2000 onwards non-exclusive. Furthermore, for care provided by nannies from 2004 onwards part- and full-time can not be distinguished anymore. In the analysis in the main text the following two variables are used. Child care enrollment comprising subsidized (daycare centers) and non-subsidized (nannies) child care for all years which can be part- or full-time, and from the year 1995 onwards the fraction of children enrolled in non-subsidized child care (nannies) from all children enrolled in child care (daycare centers and/or nannies). This latter variable assumes that the relative usage of care provided by nannies prior to 1995 was the same as the average of the years 1995 to 2007 . This strategy is only feasible because for the calibration exercise only aggregate moments are used but no individual observations.

\section{A.3 Subsidized Child Care Slot Provision}

The slot provision rates are calculated from the data provided by the German Statistical Office (Statistik der Jugendhilfe, various years). They are only available for every fourth year between 1986 and 2002. Table A.3 shows the annual averages over the years 1983 to 2006, for which the monthly labor supply status from the GSOEP is used. These averages are constructed for the two age groups zero to two, and three to six and a half as follows: Years before the earliest observation of the slot provision rates, i.e. 1983 to 1985, will be assigned the same value as the first observation of the slot provision rate (1986). Similarly, years after the last observation, i.e. 2003 to 2006, will be assigned the same value as the last observation (2002). For the years between two observations the mean of the corresponding two observations will be used. The overall provision rates are then obtained as the mean over all years. From 1994 onwards the provision rates can be further distinguished by part- and full-time from which the fraction of full-time slots from all slots, the full- 
time share, will be calculated. As for the overall provision rate, the full-time share before the first and after the last observed data points are extrapolated and between two observation interpolated. The annual provision rate of part- and full-time slots is then given by the provision rate of slots times the fraction of part- or full-time slots from all slots. The mean over all these years then finally gives the average provision rate of part- and full-time slots.

These latter rates are used to construct the success probabilities for the slot lottery. If a female would have only one draw from the slot lottery at age zero and age three, the provision rates could be immediately used as model input. There is however no way to determine how often mothers apply for a slot within a period which is regarded as a unified entity in the model. I therefore transform the observed provision rates into period equivalents in the following way: As already described for the imputation of the child care status, the majority of entries into daycare centers happens once a year. In addition, new information on the child care enrollment status is usually only once a year available. I assume that in each year a female can draw once from the lottery and a successful draw implies that the slot is open for the remainder of the period, i.e. until age three is reached or the child enters school. Once a full-time slot is drawn, the female does not have to redraw until the end of the period. Drawing a part-time slot implies that the female can redraw but success is then defined only as drawing a full-time slot because she already has access to a part-time slot for the rest of the period. Since a model period corresponds to three years I assume that within a period there is a maximum of three draws which leads to the set of possible access histories displayed in the left panel of Table A.2.

Table A.2: Access to Subsidized Child Care

\begin{tabular}{|c|c|c|c|c|c|}
\hline \multicolumn{3}{|c|}{ Access in Year } & \multirow{2}{*}{$\begin{array}{l}\text { Period } \\
\text { Mean }\end{array}$} & \multirow{2}{*}{$\begin{array}{l}\text { Access } \\
\text { Status }\end{array}$} & \multirow{2}{*}{$\begin{array}{c}\text { History } \\
\text { Probability }\end{array}$} \\
\hline 1 & 2 & 3 & & & \\
\hline No & No & No & 0 & No & $\left(1-P_{P}-P_{F}\right)^{3}$ \\
\hline No & No & Part & $1 / 6$ & No & $\left(1-P_{P}-P_{F}\right)^{2} P_{P}$ \\
\hline No & No & Full & $1 / 3$ & Part & $\left(1-P_{P}-P_{F}\right)^{2} P_{F}$ \\
\hline No & Part & Part & $1 / 3$ & Part & $\left(1-P_{P}-P_{F}\right) P_{P}\left(1-P_{F}\right)$ \\
\hline No & Part & Full & $1 / 2$ & Part & $\left(1-P_{P}-P_{F}\right) P_{P} P_{F}$ \\
\hline No & Full & Full & $2 / 3$ & Part & $\left(1-P_{P}-P_{F}\right) P_{F}$ \\
\hline Part & Part & Part & $1 / 2$ & Part & $P_{P}\left(1-P_{F}\right)^{2}$ \\
\hline Part & Part & Full & $2 / 3$ & Part & $P_{P}\left(1-P_{F}\right) P_{F}$ \\
\hline Part & Full & Full & $5 / 6$ & Full & $P_{P} P_{F}$ \\
\hline Full & Full & Full & 1 & Full & $P_{F}$ \\
\hline
\end{tabular}


Table A.3: Average Annual and Period Provision Rates of Subsidized Child Care Slots

Ages 0 to $2 \quad$ Ages 3 to 6.5

\begin{tabular}{|c|c|c|c|c|}
\hline & Annual & Period & Annual & Period \\
\hline Part-time & 0.5 & 4.3 & 62.5 & 71.5 \\
\hline & \multicolumn{2}{|c|}{$\Rightarrow$} & \multicolumn{2}{|c|}{$\Rightarrow$} \\
\hline Full-time & 1.7 & 1.7 & 14.9 & 24.2 \\
\hline
\end{tabular}

Consider the case that a female would always use as much subsidized child care as she can get access to. In line with the definition for period child care enrollment status in each year no slot is assigned a 0 , part- and full-time slots 0.5 and 1 . The mean over the whole period - the three years - is given in column 4 in Table A.2 whereas column 5 corresponds to the associated child care enrollment status for each possible access history using the same thresholds as before $(0.25$ and 0.75). Since I assume that a female does not have to use the slot she has drawn access to for some part of the period or at all, columns 4 and 5 give the period access status as opposed to the period enrollment status. Column 6 displays the probability of observing a specific access history. $P_{P}$ and $P_{F}$ are the probabilities of drawing a part- or full-time slot in a given year and correspond to the observed slot provision rates which differ by age. Finally, the probability for having access to no, a part- or full-time slot over the whole period, which then corresponds to the period provision rate, is equal to the sum of the history probabilities that are associated with the respective period access status. For example, the probability to have no slot as defined by the period access status would be the sum over the two first histories ([No, No, No], [No, No, Part-time]) and equal to $\left(1-P_{P}-P_{F}\right)^{3}+\left(1-P_{P}-P_{F}\right)^{2} P_{P}$.

Table A.3 presents the annual, i.e. observed, slot provision rates and the period provision rates after the transformation. E.g. while there are 62.5 part-time and 14.9 full-time slots per 100 children aged three to six and a half, the probability for a female that she has access to a part-time slot over the whole period where the child is between age three and six and a half is $71.5 \%$ and $24.2 \%$ for a full-time slot. Note that by construction, the period provision rates have to be larger than the annual/observed provision rates. This is also the case for children aged zero to two for the non-rounded numbers. 


\section{B Model Appendix}

Table B.1 shows in column one the fraction of females living within a certain distance to the children's grandparents, i.e. the female's or husband's parents. Columns two and three display the corresponding maternal labor force participation and child care enrollment rates for each category. This information is only available in the years 1991, 1996 and 2001 and has been matched with the corresponding period labor force participation and child care enrollment status. The last category ("Farther away") also includes females without any own parent or parent in law.

Table B.1: Minimum Distance to the Children's Grandparents

\section{Fraction Participation Enrollment}

\section{Ages 0 to 2}

Same house

$\begin{array}{ccc}13.1 & 32.4 & 1.8 \\ {[10.9 ; 15.4]} & {[23.7 ; 41.2]} & {[0.0 ; 4.3]}\end{array}$

Same neigbourhood

19.8

[17.1;22.4]

38.9

7.8

Same city

21.8

$[19.0 ; 24.6]$

[31.5; 46.3]

$[3.7 ; 11.9]$

Within $1 \mathrm{~h}$ driving distance

25.1

29.3

6.5

[22.8;35.9]

$[2.9 ; 10.1]$

$[22.2 ; 28.0]$

20.2

$[17.5 ; 22.9]$

30.7

5.2

[24.4;36.9]

[2.2;8.2]

Farther away

29.2

[22.4;36.1]

5.8

$[2.3 ; 9.4]$

\section{Ages 3 to 6.5}

Same house

11.7

$[9.5 ; 14.0]$

63.0

[53.1; 73.0]

89.1

Same neigbourhood

19.5

[16.7;22.2]

66.0

[58.5; 73.5]

Same city

21.2

[18.4;24.1]

58.1

[50.6;65.6]

Within $1 \mathrm{~h}$ driving distance

24.0

[21.1;27.0]

61.9

[55.0;68.8]

Farther away

23.5

[20.6; 26.5]

51.9

[44.7; 59.1]

[82.7; 95.5]

90.8

[86.3;95.4]

87.4

[82.4; 92.5]

81.5

[75.9;87.0]

77.8

[71.8;83.8]

\footnotetext{
Note: $95 \%$ confidence intervals are given in brackets. The information on distance to
} the (children's) grandparents is only available in the years 1991, 1996 and 2001. 


\section{Calibration Appendix}

\section{C.1 Income}

The husband's income process (Equation (23)) as well as the persistence parameter $\rho^{*}$ of the income shock $\epsilon_{t}^{*}$ (Equation (1)) are estimated directly from the data. I first calculate for each year the total annual labor income, including side jobs and self-employment, pensions, unemployment benefits (to capture the full risk of the income process), compensation for further training or education, and any additional payments as boni, $13^{\text {th }}$ and $14^{\text {th }}$ salary, vacation and Christmas pay received during the year. I then assign to each month in a year the corresponding monthly average of the corresponding annual income. Finally, the period income is defined as the sum of these average monthly incomes over all months in a period.

While for the husbands the earnings equations (23) and (1) can be estimated directly, this is more difficult for females since a consistent mapping between the measure of experience in the model and experience in the data is only feasible for females observed prior to their first birth. I therefore assume that females face the same earnings process as their husbands but take into account that they are on average 2.9 years younger and introduce a gender gap in mean wages to capture gender differences in education, occupations and potentially discrimination.

The age difference of nearly three years corresponds approximately to one model period. A female who has worked full-time in all periods, i.e. $\tilde{x}_{t}=t-1$, should receive the same (deterministic) wage a male had in the period before because of the age difference. I therefore shift the income process for husbands by one period to obtain that of females:

$$
\ln Y_{t}\left(\tilde{x}_{t}=t-1\right)=\ln Y_{t-1}^{*}=\eta_{0}^{*}+\eta_{1}^{*}(\underbrace{t-1}_{\tilde{x}_{t}}-1)+\eta_{2}^{*}(\underbrace{t-1}_{\tilde{x}_{t}}-1)^{2}+\epsilon_{t}
$$

Equation (C.1) can then be reformulated to obtain the coefficients of the female income process:

$$
\ln Y_{t}=\underbrace{\eta_{0}^{*}-\eta_{1}^{*}+\eta_{2}^{*}}_{\eta_{0}}+\underbrace{\left[\eta_{1}^{*}-2 \eta_{2}^{*}\right]}_{\eta_{1}} \tilde{x}_{t}+\underbrace{\eta_{2}^{*}}_{\eta_{2}} \tilde{x}_{t}^{2}+\epsilon_{t}
$$

This implies that in the model in a given period, where husbands and females by construction have the same age, females have a lower mean wage and face larger returns to experience than their spouses if $\eta_{2}^{*}<0$. Using the full-time log wages of both sexes prior to the first birth, ${ }^{25}$ the gender wage gap in mean income controlling for age can be estimated and added to the log of the gross income:

$$
\eta_{0}=\eta_{0}^{*}-\eta_{1}^{*}+\eta_{2}^{*}+\Delta_{\text {gender }}
$$

This procedure is similar to the one used by Guner, Kaygusuz, and Ventura (2010). The last missing piece of the income process concerns the stochastic part (Equation (1)) where I follow Attanasio, Low, and Sanchez-Marcos (2008) and use the male estimates for the females. Table C.1 summarizes the estimation results on the income process.

\footnotetext{
${ }^{25}$ By then $75 \%$ of the females are working full-time.
} 
Table C.1: Income Process

Estimate

Gender wage gap

$\Delta_{\text {gender }}-0.245$

Deterministic part

$\begin{array}{lrr}\eta_{0}^{*} / \eta_{0} & 11.647 / & 11.343 \\ \eta_{1}^{*} / \eta_{1} & 0.051 / & 0.065 \\ \eta_{2}^{*} / \eta_{2} & -0.007 / & -0.007\end{array}$

Stochastic part

$\rho^{*}, \rho$

$\sigma_{\varepsilon^{*}}, \sigma_{\varepsilon} \quad 0.272$

Note: Estimation based on incomes in $2008 €$. $\eta_{0}$ is calculated as in Equation (C.3) and $\eta_{1}, \eta_{2}$ as in Equation (C.2).

\section{C.2 Taxation and Transfers}

The tax code is based on the average income taxes over the sample period in $2008 €$, which are available (in nominal terms) for each year on the website of the German Federal Ministry of Finance (https://www.abgabenrechner.de/). The tax code consists of three parts separated by two thresholds. First, annual incomes up to $3282 €$, the smallest income tax allowance in the years 1983 to 2006, are tax-exempted. Second, every $€$ above $100,000 €$ is taxed linearly at a marginal rate of $52 \%$. Third, every $€$ between the two thresholds is taxed at an increasing marginal rate. The coefficients for this part are obtained by regressing the average tax burden over the sample period on a seventh order polynomial of taxable income, i.e. income less the tax allowance. The upper threshold of 100,000€ was chosen because for higher incomes the average marginal taxes does not change anymore. Figure C.1 and Table C.3 summarize the information on the progressivity of the tax code implemented in this paper. 
Table C.2: Monthly Social Security Contributions

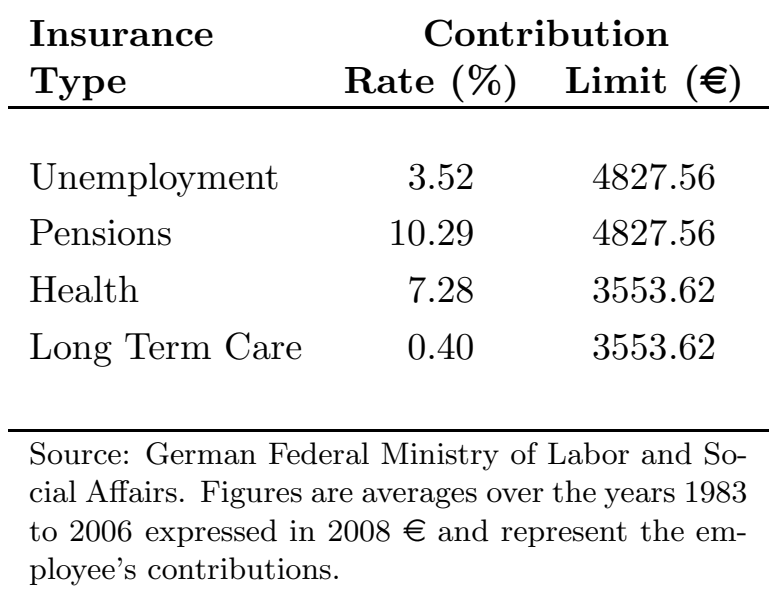

Table C.3: Annual Taxes

Taxable Income Tax Burden

$0-3282 \quad 0$

\begin{tabular}{c}
\hline $3283-100000 \quad \sum_{i=1}^{7} \beta_{i}(y-3282)^{i}$ \\
$\beta_{1}=.07415027$ \\
$\beta_{2}=.00001249$ \\
$\beta_{3}=-3.990 \mathrm{e}-10$ \\
$\beta_{4}=9.011 \mathrm{e}-15$ \\
$\beta_{5}=-1.143 \mathrm{e}-19$ \\
$\beta_{6}=7.456 \mathrm{e}-25$ \\
$\beta_{7}=-1.964 \mathrm{e}-30$ \\
\\
$100001-\infty \quad \sum_{i=1}^{7} \beta_{i}(1 \mathrm{e} 5-3282)^{i}+(\mathrm{y}-1 \mathrm{e} 5) \times 0.52$ \\
\hline \\
Source: German Federal Ministry of Finance, own calculations. Fig- \\
ures are averages over the years 1983 to 2006 expressed in $2008 €$.
\end{tabular}


Figure C.1: Annual Tax Burden and Average Tax Rate

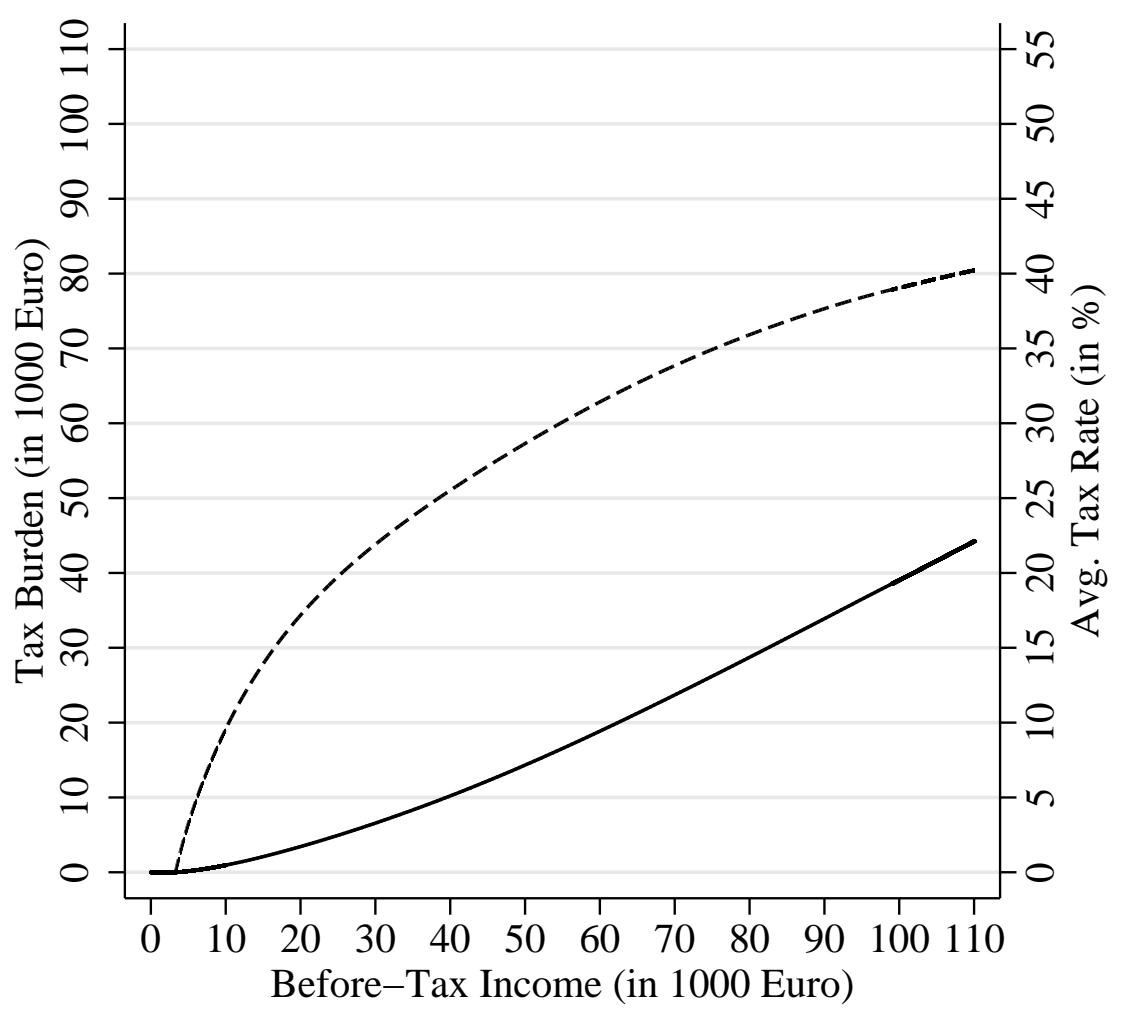

\section{Tax Burden $\quad------$ Avg. Tax Rate}

Source: German Federal Ministry of Finance, own calculations. Figures are averages over the years 1983 to 2006 expressed in $2008 €$.

Table C.4: Child Benefits

\section{Number of Children Benefits}

$\begin{array}{lr}1 & 93.99 \\ 2 & 210.23 \\ 3 & 379.78\end{array}$

Source: German Federal Ministry of Finance. Figures are averages over the years 1983 to 2006 expressed in $2008 €$. 


\section{C.3 Child Care Fees}

Table C.5: Monthly Per Child Fees - Regression Coefficients

\begin{tabular}{|c|c|c|}
\hline & Subs. & Non-Subs. \\
\hline Intercept & 53.79 & 236.49 \\
\hline Full-time & 50.20 & 177.52 \\
\hline Ages 0 to 2 & 21.90 & - \\
\hline $\begin{array}{l}\text { Siblings in } \\
\text { subsidized child care }\end{array}$ & -29.56 & - \\
\hline Household income ${ }^{\dagger}$ & 0.02 & - \\
\hline \multicolumn{3}{|c|}{$\begin{array}{l}\text { Note: The coefficients for subsidized child care are ob- } \\
\text { tained from a Tobit regression from all children in the } \\
\text { selected sample enrolled in subsidized child care with cen- } \\
\text { soring at } 0 € \text { and at } 447.72 € \text {, the lowest and highest ob- } \\
\text { served monthly fee for subsidized child care. Due to the } \\
\text { low usage of non-subsidized child care the coefficients for } \\
\text { non-subsidized care are obtained from all children in the } \\
\text { GSOEP in non-subsidized child care by an OLS regression. } \\
\text { The information about fees that also allows to distinguish } \\
\text { between subsidized and non-subsidized child care is only } \\
\text { available in the years } 1996,2002 \text { and } 2005 \text { and were trans- } \\
\text { formed into } 2008 € \text {. }\end{array}$} \\
\hline
\end{tabular}


Table C.6: Monthly Per Child Fees - Predicted Values

Subs. Non-Subs.

\section{Baseline fee}

Part-time

Ages 3 to 6.5

No siblings

Median household income ${ }^{\dagger}$

\section{Extra Charges}

$\begin{array}{llll}\text { Full-time } & (+) & 46 & 177 \\ \text { Ages 0 to 2 } & (+) & 19 & -\end{array}$

Siblings in subsidized child care

One further $\quad(-) \quad 27$

Two further (-) 45

Household income is $(+) \quad 30$

twice the median

Note: The fees are expressed in $2008 €$ and are predicted values from the regressions reported in Table C.5.

$\dagger$ The median household income in the sample with children in subsidized child care amounts to $4583 €$ per month and is further deflated by the OECD (Oxford) equivalence scale to account for household size. A two parent, one child household is assumed for the baseline fees and in case of the sibling discount two and three children are used for the application of the equivalence scale.

Non-subsidized child care is estimated to be three to four times as expensive as subsidized child care.This estimate seems very plausible as around $75 \%$ of the operating expenses per subsidized child care slot are covered by the subsidy, see Kolvenbach, Haustein, Krieger, Seewald, and Weber (2004). 


\section{Model Evaluation Appendix}

In this section I discuss a set of non-targeted moments which were were only touched on in the presentation of stylized facts in Section 3.

The left panel of Figure D.1 shows that the part-time maternal labor force participation rate is predicted very well also for the non-targeted periods three to five. In contrast, the full-time maternal labor force participation rate in the data increases during periods three to four but decreases slightly in the model. This can be explained by the dominance of the participation-decreasing effect of the increasing husbands' income (see Figure 7) over the participation-increasing effect of the decreasing utility from spending time with the children. In the fifth period the latter effect dominates the former such that the full-time maternal labor force participation rate in the model increases and is very close to the data.

Figure D.1: Model Fit - Part- vs. Full-time Rates
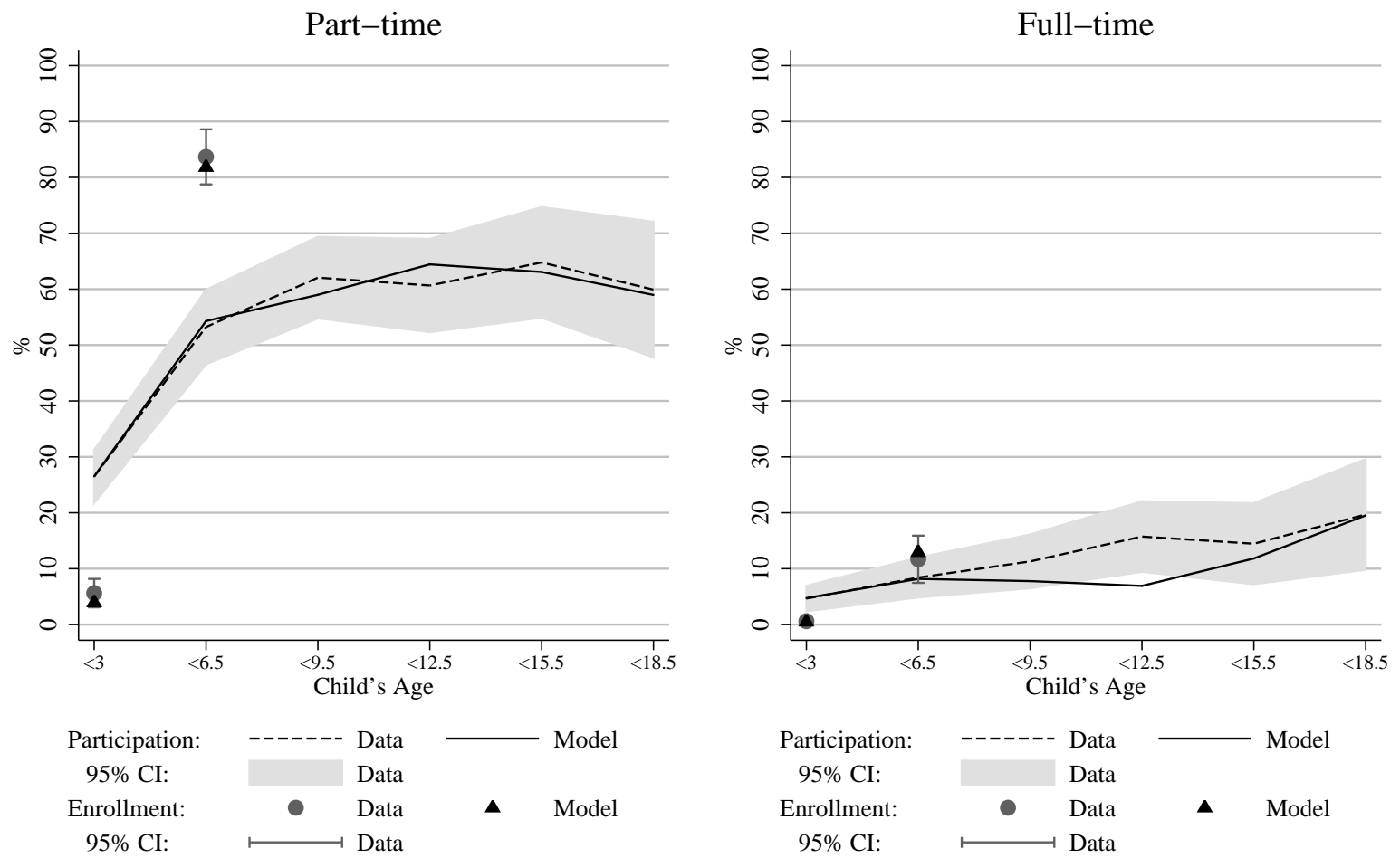

Recall that the average part- and full-time maternal labor force participation rate in periods one, two and six were used as targets. Figure D.2 documents the part- and full-time maternal labor force participation rates broken down by the number of children. The just described behavior of the full-time labor force participation rates during periods three to five is common to all parities. For females with one child part-time labor force participation is too high relative to the data, particularly once children enter school, whereas the opposite is true for the full-time labor force participation rate. For females with two children, which represent more than half of all females 
Figure D.2: Model Fit - Part- vs. Full-time Rates by the Number of Children

1 child
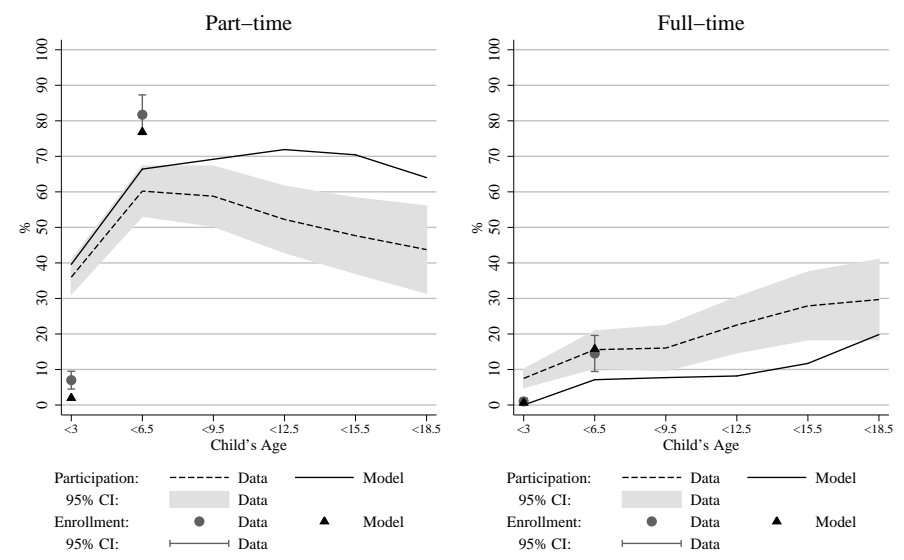

2 children
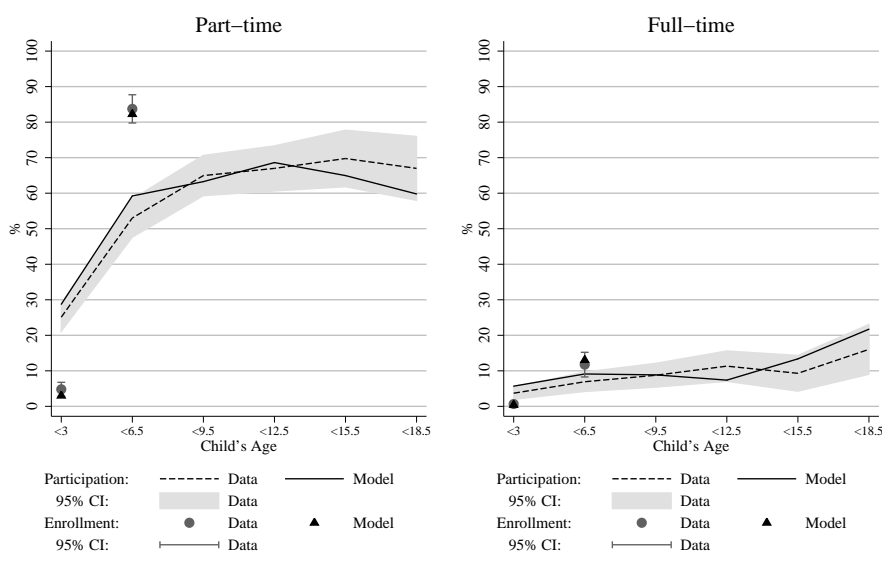

3 children
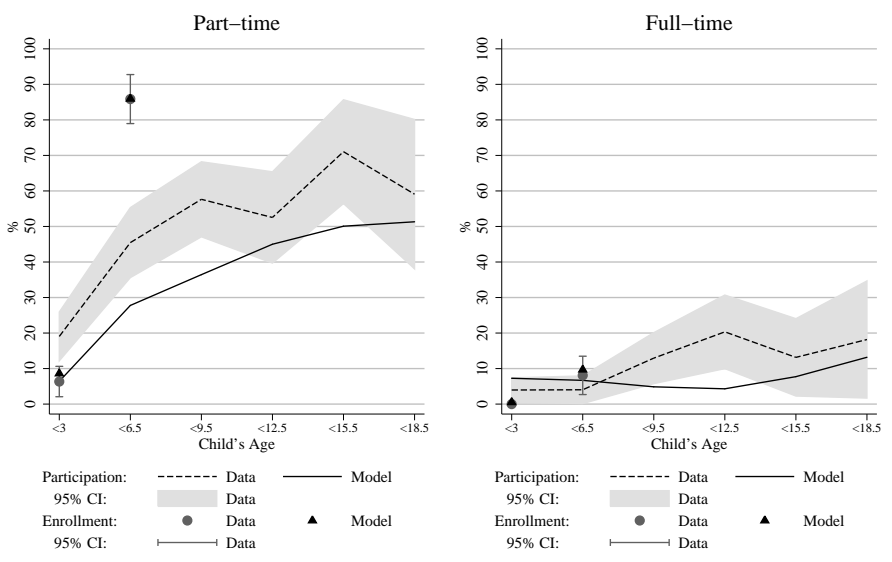
and all mothers in the sample, both labor force participation rates are predicted fairly well and fall within the $95 \%$ confidence intervals. For females with three children both rates in the model are lower than the actual ones with the exception of the full-time labor force participation rate in the first two periods. The part- and full-time child care enrollment rates by the number of children are matched precisely. Although for mothers with one child the part-time child care enrollment rates are not within the $95 \%$ confidence intervals, the qualitative facts, i.e. a low (high) part-time child care enrollment rate for children aged zero to two (three to six and a half), are predicted correctly by the model.

The overprediction of part-time labor force participation of mothers with one child and the underprediction of labor force participation of mothers with three children is linked to the fertility choice. Differences in fertility outcomes stem from the heterogeneity of the initial productivity/income shocks of both spouses, see Figure D.3. Note that the probability of observing a certain combination of initial income shocks is not equally distributed but concentrated (symmetrically) around the center of the graph. Generally, fertility is increasing in the initial income shock of one spouse holding fixed the other spouse's initial income shock. ${ }^{26}$ Jones, Schoonbroodt, and Tertilt (2001) discuss the fertility-income relationship for various models. Similar to the result presented here, they show that in a static model with child care as a substitute for maternal time, fertility is increasing in household income. This relationship is responsible for the differences in the labor force participation rates between the model and data for females with one and three children. The former are on average (due to the persistence of the shock) of lower productivity types and therefore rather work part- than full-time. This force is stronger than the relatively low incomes of their husbands which in principle would provide an incentive for more females with one child to work full-time. The combination of low productivity females and husbands also explains the low part-time child care enrollment rate in the model relative to the data. Some of these females prefer to incur the utility loss of using non-paid child care over the consumption loss of using paid child care. In contrast, females with three children have a lower incentive to work part- and full-time because their husbands have a higher initial productivity (which is persistent over time) and thus a higher income on average, see Figure D.3. Only in the first two periods, where the husbands' incomes are relatively low (compared to later in life), more females with three children are working full-time in the model relatively to the data because they are themselves of a high productivity type.

Given the structure of the model employed in this paper, a direct comparison between the fertilityincome relationship in the data and the model is not possible. As an approximation Table D.1 shows the coefficients from an OLS regression of the total number of children on an intercept and education dummies for the female and the husband. In the data, high education is defined as having at least a vocational degree plus the permission to attend college (Fachhochschule/Universität) or a college degree. In the model, high education is defined as having an above mean initial income shock and in the regression each spousal productivity combination is weighted according to the stationary distribution. The intercept in the model regression of 0.95 reflects the large fraction of low educated couples with zero children, compare Figure D.3. ${ }^{27}$ In the data, low income couples

\footnotetext{
${ }^{26}$ Three exceptions break this monotonicity. In contrast to their "neighbors", couples with the lowest initial productivity shock combination choose three children because their income is that low that the income gain through the child benefits outweighs the decrease in the female's consumption share through the presence of the children. The two other exceptions stem from the interaction of the non-linear child care fees and benefits with the child-dependent equivalence scale in the budget constraint.

${ }^{27}$ Note that the couples with the lowest initial productivity shock combination (who have three children) only
} 
Figure D.3: Fertility and Income in the Model
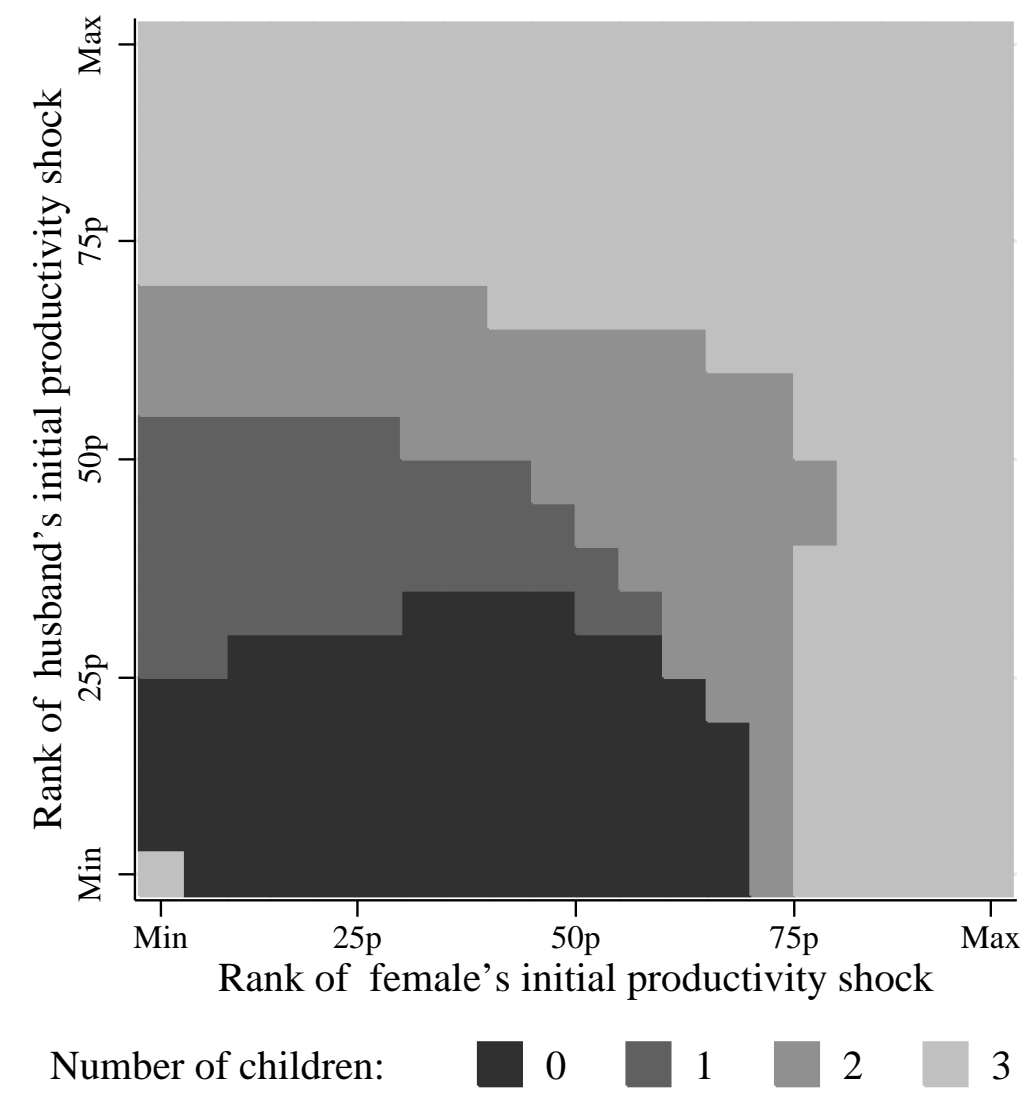

have on average much more children which is reflected by the higher intercept (1.63). While the size of the education effects is not matched, the model replicates that the husband's education is a stronger predictor for fertility than the female's education by a similar magnitude in absolute terms $\left(\frac{0.20}{0.12}=1.7\right.$ vs. $\left.\frac{1.07}{0.59}=1.8\right)$. However, in the model also the female's education raises the number of children while there is no statistically significant effect in the data.

enter with a weight of $0.000015 \%$. 
Table D.1: Fertility and Income in the Data and the Model

\begin{tabular}{lcl} 
& Data & Model \\
\hline \multirow{3}{*}{ Intercept } & $1.63^{* * *}$ & $0.95^{* * *}$ \\
& $(0.04)$ & $(0.05)$ \\
High Educated Female & -0.12 & $0.59^{* * *}$ \\
& $(0.07)$ & $(0.06)$ \\
High Educated Husband & $0.20^{* * *}$ & $1.07^{* * *}$ \\
& $(0.07)$ & $(0.06)$
\end{tabular}

Note: Standard errors are give in parentheses. ${ }^{* * *} /{ }^{* *} /{ }^{*}$ indicate significance at the $1 \% / 5 \% / 10 \%$ level. In the regression for the model the stationary distribution was used for weighting. 